\title{
EXPERIÊNCIAS INVESTIGATIVAS NO ENSINO DE CIÊNCIAS
}

\author{
Nívia Magalhães da Silva Freitas \\ Elinete Raposo Ribeiro \\ Nadia Magalhães da Silva Freitas \\ Organizadoras
}

Cássia Nunes Leão - Chirla Miranda da Costa - Darlene Teixeira Ferreira - Erllon Rodolfo Viegas Barata - Josyane Barros de Abreu Lidiane Amaral Barbosa - Michelli Staudt - Paulo Vilhena da Silva Renan Ferreira Freitas - Sebastião Nogueira da Fonseca Neto 


\section{EXPERIÊNCIAS INVESTIGATIVAS NO ENSINO DE CIÊNCIAS}

Nívia Magalhães da Silva Freitas

Elinete Raposo Ribeiro

Nadia Magalhães da Silva Freitas

Organizadoras

Cássia Nunes Leão - Chirla Miranda da Costa - Darlene Teixeira Ferreira - Erllon Rodolfo Viegas Barata - Josyane Barros de Abreu Lidiane Amaral Barbosa - Michelli Staudt - Paulo Vilhena da Silva Renan Ferreira Freitas - Sebastião Nogueira da Fonseca Neto. 
(C 2020 por Nívia Magalhães da Silva Freitas, Elinete Raposo Ribeiro e Nadia Magalhães da Silva Freitas (org.)

Todos os direitos reservados.

\author{
Conselho editorial \\ Colaboradores: \\ Márcia Aparecida da Silva Pimentel \\ Universidade Federal do Pará - UFPA \\ José Antônio Herrera \\ Universidade Federal do Pará - UFPA \\ Bruno Nunes Batista \\ Instituto Federal Catarinense - IFC \\ Wildoberto Batista Gurgel \\ Universidade Federal Rural do Semi-Árido - UFERSA \\ André Luiz de Oliveira Brum \\ Universidade Federal do Rondônia - UNIR \\ Mário Silva Uacane \\ Universidade Licungo / Moçambique \\ Francisco da Silva Costa \\ Universidade do Minho / Portugal \\ Ofelia Pérez Montero \\ Universidad de Oriente- Santiago de Cuba-Cuba \\ Editora-chefe \\ Viviane Corrêa Santos \\ (Universidade do Estado do Pará - UEPA)
}

Preparação e organização dos originais: Deividy Barbosa.

Capa e editoração eletrônica: Walter Rodrigues.

Dados Internacionais de Catalogação na Publicação (CIP) de acordo com ISBD

E96 Experiências investigativas no ensino de ciências [recurso eletrônico] / Nívia Magalhães da Silva Freitas, Elinete Raposo Ribeiro, Nadia Magalhães da Silva Freitas (Organizadores). - Ananindeua, PA : Itacaiúnas, 2020.

80 p. ; PDF ; 2 MB.

Vários autores

Inclui bibliografia e índice.

ISBN: 978-65-990164-8-6 (Ebook)

1. Ciências. 2. Ensino de Ciências. 3. Experiências. 4. Docência. 5. Tecnologia. 6. Sociedade. I. Título.

Elaborado por Vagner Rodolfo da Silva - CRB-8/9410

Índice para catálogo sistemático:

1. Ciências 550

2. Ciências 55

DOI 10.36599/itac-ed1.005

O conteúdo desta obra, inclusive sua revisão ortográfica e gramatical, bem como os dados apresentados, é de responsabilidade de seus participantes, detentores dos Direitos Autorais. Esta obra foi publicada pelaEditora Itacaiúnas em abril de 2020. 


\section{APRESENTAÇÃO}

A obra é fruto de Experiências investigativas no Ensino de Ciências, desenvolvidas no contexto da formação inicial de professores, no âmbito do Instituto de Educação Matemática e Científica (IEMCl), da Universidade Federal do Pará (UFPA). Destaca-se pela qualidade e diversidade de temas abordados.

Motivados por diálogos e reflexões provenientes de nossa experiência docente, momento em que transformamos nossa sala de aula em espaço de desenvolvimento de pesquisa e de produção de conhecimento, que conduziu este grupo de professores a socializar suas experiências (de ensino e de pesquisa), ultrapassando os muros das escolas e chegando à mão de muitos outros professores.

Este livro é constituído por cinco capítulos que abordam experiências distintas com temas que denotam a preocupação por questões de relevância socioambiental, principalmente aquelas em que se destacam o contexto amazônico e a abordagem Ciências, Tecnologia e Sociedade (CTS).

O primeiro capítulo, "Consumo e sustentabilidade: uma abordagem à pegada ecológica no ensino de ciências", traz a análise de uma experiência formativa, nos moldes de um estudo de caso no ensino, que discutiu a problemática do consumo a partir da atividade "pegada ecológica", que estimulou os alunos a produzirem uma "Carta Aberta à Sociedade" como atividade final da estratégia de ensino. $\bigcirc$ capítulo "Mediações teatrais no ensino do corpo humano: contribuições para a formação de professores e o fazer docente diferenciado" apresenta a análise de uma intervenção pedagógica, mediada pelo teatro, para tratar do tema corpo humano e saúde, com ênfase em sua dimensão social. O terceiro capítulo, "Música no varal": a educação para a sustentabilidade na/para a Amazônia", é parte de uma pesquisa intitulada "Energia e sustentabilidade", que visou analisar os limites e as possibilidades de uma abordagem de ensino com enfoque CTS. Para este livro, foi utilizada a análise crítica da música 'Saga da Amazônia", de Vital Farias.

Os capítulos quatro e cinco analisam diferentes aspectos de uma ação pedagógica, que teve por tema "usos e abusos da energia nuclear", a partir da abordagem CTS. Tal estudo foi desenvolvido por meio de diversas atividades, como exemplo a análise de fotografias, filmes, músicas, produções textuais e debates, frente a uma questão sociocientífica. Assim, o capítulo "O lúdico na apreensão das questões 
CTS" refere-se à análise crítica da canção "Rosa de Hiroshima", de Vinícius de Moraes, e o capítulo "Relação entre ciência, tecnologia e sociedade: o que pensam os alunos da licenciatura integrada" analisa respostas a um questionário que se propôs a revelar a concepção dos graduandos em relação à necessidade de uma formação científica em um mundo marcado pela presença da ciência e da tecnologia, assim como sobre a importância do enfoque CTS para a educação, de um modo geral, e, de forma mais específica, para o ensino de ciências.

A expectativa desta obra é inspirar professores ou futuros professores da educação básica e/ou superior a tratar em suas aulas questões de relevância social, de modo a contribuir com a formação cidadã. Boa leitura!

Nívia Magalhães da Silva Freitas

Elinete Raposo Ribeiro Nadia Magalhães da Silva Freitas

(As organizadoras) 


\section{ORGANIZADORAS}

Nívia Magalhães da Silva Freitas. Bacharel em Medicina Veterinária, pela Universidade Federal Rural da Amazônia. Licenciada em Ciências Biológicas, pelo Centro Universitário Leonardo da Vinci. Especialista em Microbiologia, pela Universidade Federal do Pará. Mestra em Saúde e Produção Animal na Amazônia, pela Universidade Federal Rural da Amazônia. Doutora em Educação em Ciências (área de concentração em Educação em Ciências), pela Universidade Federal do Pará. Professora Colaboradora da Universidade Federal do Pará. E-mail: nivia.bio2015@gmail.com

Elinete Raposo Ribeiro. Graduada em Licenciatura Plena em Física, pela Universidade Federal do Pará. Especialista em Educação em Problemas Regionais, pela Universidade Federal do Pará. Mestra e Doutora em Educação em Ciências e Matemáticas (área de concentração em Educação em Ciências), ambos pela Universidade Federal do Pará. Professora Adjunta do Instituto de Educação Matemática e Científica. Email: elinete@ufpa.br

Nadia Magalhães da Silva Freitas. Bacharel em Nutrição, pela Universidade Federal do Rio de Janeiro. Mestra em Ciências (Microbiologia), pela Universidade Federal do Rio de Janeiro. Doutora em Desenvolvimento Sustentável do Trópico Úmido, pela Universidade Federal do Pará. Pós-Doutora em Ensino e Aprendizagem das Ciências, pela Universidade Federal de Santa Catarina. Professora Titular da Universidade Federal do Pará. E-mail: nadiamsf@yanoo.com.br 


\section{AUTORES}

Cássia Nunes Leão. Graduada em Licenciatura Integrada em Educação em Ciências, Matemática e Linguagens, pela Universidade Federal do Pará. Especialista em Psicopedagogia Institucional e Clínica, pela Faculdade de Administração, Ciências, Educação e Letras. E-mail: cassialeao_nunes@hotmail.com

Chirla Miranda da Costa. Graduada em Licenciatura em Ciências Biológicas, pela Universidade Federal do Pará. Mestra em Educação em Ciências e Matemáticas (área de concentração em Educação em Ciências), pela Universidade Federal do Pará. Doutoranda do Programa de Educação em Ciências e Matemáticas, pela Universidade Federal do Pará. E-mail: chirlamiranda@gmail.com

Darlene Teixeira Ferreira. Graduada em Licenciatura em Ciências Naturais, habilitação em Biologia, pela Universidade Federal do Pará. Especialista em Gestão Ambiental, pela Universidade Federal do Pará. Mestra e Doutora em Educação em Ciências e Matemáticas (área de concentração em Educação em Ciências), ambos pela Universidade Federal do Pará. Professora Adjunta da Universidade Federal do Pará. Email: darfei1 @yahoo.com.br

Erllon Rodolfo Viegas Barata. Graduado em Licenciatura Plena em Pedagogia, pela Faculdade Integrada Brasil Amazônia. Especialista em Estudos Contemporâneos do Corpo, pela Universidade Federal do Pará. Mestrando do Programa de Educação em Ciências e Matemáticas, pela Universidade Federal do Pará. E-mail: erlon.rodolfo@gmail.com

Josyane Barros de Abreu. Graduada em Licenciatura em Ciências Biológicas, pela Universidade Federal do Pará. Doutoranda do Programa de Pós-Graduação em Educação em Ciências e Matemáticas, pela Universidade Federal do Pará. E-mail: josyanebarros@gmail.com

Lidiane Amaral Barbosa. Graduada em Licenciatura Plena em Ciências Biológicas, pela Universidade Federal do Pará. Graduanda de Licenciatura Plena em Pedagogia, pela Universidade Cruzeiro do Sul. Mestra em Educação em Ciências e Matemáticas lárea de concentração em Educação em Ciências). E-mail: lidibarbosa2010@hotmail.com

Michelli Staudt. Graduada em Licenciatura em Ciências Biológicas, pela Universidade Federal do Pará. Mestra em Educação, pela Universidade de Passo Fundo. E-mails: biostaudt@gmail.com 
Paulo Vilhena da Silva. Graduado em Licenciatura Plena em Matemática, pela Universidade Federal do Pará. Mestre e Doutor em Educação em Ciências e Matemáticas (área de concentração em Matemática), ambos pela Universidade Federal do Pará. Professor Adjunto da Faculdade de Matemática, da Universidade Federal do Pará. E-mail: pvilhena@ufpa.br

Renan Ferreira Freitas. Graduada em Licenciatura Integrada em Educação em Ciências, Matemática e Linguagens, pela Universidade Federal do Pará. Mestre em Educação em Ciências e Matemáticas (área de concentração em Educação em Ciências). Doutorando do Programa de Pós-Graduação em Ciências e Matemática, pela Universidade Federal do Paraná. E-mail: renanferreira2@yahoo.com

Sebastião Nogueira da Fonseca Neto. Graduado em Licenciatura Plena em Física, pela Universidade Federal do Pará. Especialista em Docência do Ensino Superior. Mestre em Educação em Ciências e Matemáticas (área de concentração em Educação em Ciências). Professor da educação básica e tecnológica do estado do Pará. E-mail: nfneto@hotmail.com 


\section{PREFÁCIO}

O livro "Experiências Investigativas no Ensino de Ciências", na sua versão E-Book, organizado por professores da Universidade Federal do Pará, é composto por uma coletânea de textos que tratam de resultados de uma agenda de pesquisa realizada por alunos de pósgraduação e professores, por meio de um qualificado esforço de problematizar determinados contextos e conteúdos de ensino, no campo das ciências, não se atendo às amarras rigorosas da ciência clássica e do enfeudamento disciplinar. A tarefa desafiante de apresentá-lo ao público veio de um gentil convite da Profa. Dra. Nádia Magalhães da Silva Freitas, coordenadora do Grupo de Estudo e Pesquisa "Educação em Ciências e Sustentabilidade na Amazônia", vinculado ao Programa de Pós-Graduação em Ciências e Matemáticas (PPGECM), da Universidade Federal do Pará.

As experiências investigadas foram refletidas à luz de expressões teóricas e dialógicas com autores que dão conta do debate atual, revestindo as problemáticas analisadas de relevância sociocientífica. A convergência de pressupostos que sustentam as análises abre possibilidade para se localizar o debate sobre o ensino das ciências em um campo interdisciplinar. Simples assim, evidente que não, essa perspectiva teórico metodológica carrega consigo um grande desafio. Ao apreciar os textos foi possível identificar uma conexão interdisciplinar entre eles, o que fertiliza a inserção da coletânea no debate sobre temas que informam ou fazem interface com o ensino das ciências, instituindo, desta forma, questões de interesse epistemológico e acadêmico.

Fruto de experiências de pesquisas de um grupo de alunos/as e professoras/es vinculados à pós-graduação, no campo do ensino de ciências, os textos dão uma ideia de concretude e criatividade, sem 
deixar de lado o necessário rigor científico; conformam-se dialeticamente em inter-relações teoria e prática. Uma vez que os trabalhos foram elaborados sob diferentes enfoques teóricos e metodológicos, seus autoras/es recorrem a diversas linguagens (música, teatro, narrativas fictícias, atividades lúdicas etc.) e outras formas de representações simbólicas.

Os trabalhos problematizam uma série de matizes que informam e/ou dão conta do debate em relação à "questão ambiental", que guarda relação ou está na origem da denominada "crise ecológica"; colocam em relevo desde a racionalidade técnico instrumental econômica, que tem orientado, de forma acentuada, o processo de industrialização e indução do consumo exacerbado.

A educação e a formação de professores são acionadas como um dos caminhos e contribuição possível em direção à transição para a sustentabilidade das sociedades. A partir de então, as/os autoras/es destacam, no contexto dos processos educacionais, o "ensino de ciências naturais" como uma ferramenta importante para ampliar a compreensão sobre os fatores que podem estar associados à problemática, agora reconhecida como de natureza socioambiental. Dessa forma, nesse contexto de reflexão e análise, a ideia de sustentabilidade é mobilizada para colocar em debate a questão do consumo e suas interfaces.

Assim, dois aspectos merecem ser destacados. O primeiro, a iniciativa e o envolvimento de um conjunto de sujeitos históricos, que, a partir de uma convivência que poderia ter sido estritamente pedagógica, foram trabalhados como oportunidade de educação científica e de encontros para o alargamento da construção de espaços de produção de saberes, por meio de experiências de pesquisa. O segundo, claramente explicitado nas temáticas que deram título aos textos, refere-se à convergência do debate entre campos do conhecimento. 
Por contribuir para a renovação de uma agenda de estudos e pesquisas que tratam de temas que conformam um diálogo entre educação, ensino e ciências, alguns mediados por ferramentas pedagógicas de natureza simbólica, o presente livro merece leitura atenta e proveitosa. Assim desejamos!

Maria das Graças da Silva Professora e Pesquisadora da Universidade Estadual do Pará 


\section{SUMÁRIO}

CONSUMO E SUSTENTABILIDADE: UMA ABORDAGEM À PEGADA ECOLÓGICA NO ENSINO DE CIÊNCIAS

Darlene Teixeira Ferreira

Michelli Staudt

Nívia Magalhães da Silva Freitas

Elinete Oliveira Raposo

Nadia Magalhães da Silva Freitas

MEDIAÇÕES TEATRAIS NO ENSINO DO CORPO HUMANO: CONTRIBUIÇÕES

PARA A FORMAÇĀO DE PROFESSORES E O FAZER DOCENTE DIFERENCIADO

Erllon Rodolfo Viegas Barata

Cássia Nunes Leão

Renan Ferreira Freitas

Nívia Magalhães da Silva Freitas

Darlene Teixeira Ferreira

Nadia Magalhães da Silva Freitas

"MÚSICA NO VARAL": A EDUCAÇÃO PARA A SUSTENTABILIDADE NA/PARA

A AMAZÔNIA

Sebastião Nogueira da Fonseca Neto

Nívia Magalhães da Silva Freitas

Paulo Vilhena da Silva

Nádia Magalhães da Silva Freitas

O LÚDICO NA APREENSÃO DAS QUESTÕES CTS

Josyane Barros de Abreu

Darlene Teixeira Ferreira

Nívia Magalhães da Silva Freitas

Chirla Miranda da Costa

Elinete Oliveira Raposo

Nadia Magalhães da Silva Freitas

RELAÇÃO ENTRE CIÊNCIA, TECNOLOGIA E SOCIEDADE: O QUE PENSAM OS ALUNOS DA LICENCIATURA INTEGRADA

Lidiane Amaral Barbosa

Darlene Teixeira Ferreira

Nívia Magalhães da Silva Freitas

Josyane Barros Abreu

Elinete Oliveira Raposo

Nadia Magalhães da Silva Freitas 


\title{
CONSUMO E SUSTENTABILIDADE: UMA ABORDAGEM À PEGADA ECOLÓGICA NO ENSINO DE CIÊNCIAS ${ }^{1}$
}

\author{
Darlene Teixeira Ferreira \\ Michelli Staudt \\ Nívia Magalhães da Silva Freitas \\ Elinete Oliveira Raposo \\ Nadia Magalhães da Silva Freitas
}

\section{INTRODUÇÃO}

Os desequilíbrios nos ecossistemas indicam que há algo errado e que é preciso repensar o modelo de relacionamento entre os seres humanos e os recursos naturais. Isso porque as ações antrópicas estão acelerando os processos de instabilidades dos sistemas naturais, ocasionando o que Leis (2001) denominou de "desordem global da biosfera". Essa desordem resultou em uma crise ecológica que, de acordo com Leff (2002, p. 59), "[...] emergiu nas últimas décadas do século XX, como uma crise de civilização, questionando a racionalidade econômica e tecnológica dominantes".

Por sua vez, Portilho (2005, p. 24) destaca que "[...] não existe uma crise ambiental única, mas uma pluralidade de formas de definição e problematização da mesma e uma disputa por proposições e tentativas de soluções em diferentes setores sociais". Atualmente, há uma variedade de fatores que podem ser responsabilizados pelo surgimento dessa crise, que afeta todas as dimensões da sociedade. Entre esses fatores, encontramos o consumo.

A questão do consumo, de acordo com Zacarias (2009, p. 119), "[...] vem sendo pauta de estudos de diversos autores no mundo contemporâneo", e há várias explicações para o evento. Ainda, segundo Zacarias (2009, p. 119), esses estudos "[...] aceitam a tese de

\footnotetext{
1 Publicado originalmente no IX Encontro Nacional de Pesquisa em Educação em Ciências, em 2013, revisado e atualizado.
} 
que o fator organizador da sociedade contemporânea encontra-se na esfera do consumo e não na da produção". Portilho (2005) afirma que, ao longo das últimas décadas, os fatores responsáveis pela degradação ambiental foram se alterando e, a partir disto, as discussões ganharam novas dimensões. Segundo a autora, o crescimento demográfico foi considerado como o primeiro evento responsável pela pressão sobre os recursos naturais.

É bem verdade que o argumento demográfico ocupou um lugar importante no debate do final dos anos 1960 e do início dos anos 1970 (SACHS, 2007). No entanto, foi contestado por três reflexões, a saber: a principal delas afirma que a limitação do número de consumidores não reduziria de forma considerável a pressão exercida sobre os recursos naturais. Mesmo porque o que deve ser levado em consideração são os seguintes aspectos: o estilo de vida, os modelos de consumo e as tecnologias, uma vez que nem todos os habitantes do nosso planeta têm a possibilidade de usufruir dos bens produzidos a partir dos recursos naturais.

Assim, o problema não pode ser atribuído à quantidade de pessoas, mas à intensidade crescente com que uma pequena parcela da população mundial passou a utilizar os produtos oriundos do processo de industrialização. Conforme Portilho (2005), iniciava-se o primeiro deslocamento do crescimento demográfico para a questão da produção.

Com a realização da Conferência das Nações Unidas sobre o Meio Ambiente Humano (Conferência de Estocolmo)2, em 1972, os países em desenvolvimento apontaram as nações industrializadas como as principais implicadas na crise ambiental, uma vez que as indústrias precisavam de uma grande quantidade de matéria-prima, gerando uma série de impactos nos ecossistemas. Desse modo, os governos

2 Primeira grande reunião de chefes de estado, mediada pela Organização das Nações Unidas (ONU), para discutir questões relacionadas à degradação ambiental, realizada entre os dias 5 a 16 de junho de 1972 na capital da Suécia, Estocolmo. 
passaram a estabelecer novas regras e exigências, forçando a incorporação da pauta ambiental nos processos produtivos.

É a partir da década de 1990, durante as preparações da Rio 9233, de acordo com Portilho (2005), que a problemática ambiental foi redefinida, passando a ser relacionada com os altos padrões de consumo das sociedades e das classes emergentes. Portanto, evidencia-se o segundo deslocamento, da produção para o consumo. Portilho (2005, p. 27) afirma o seguinte: "[...] este segundo deslocamento da definição da questão ambiental coincide e pode ser explicado a partir da tendência de mudança paradigmática do princípio estruturante e organizador da sociedade, da produção para o consumo". Com a emergência do consumo como fator principal da crise ambiental, novos debates ocorreram na tentativa de minimizar os efeitos da crise.

No centro do debate, encontrava-se a educação como um dos fatores que poderia contribuir, de forma significativa, para a construção de uma sociedade sustentável. De fato, entendemos que a educação, em especial o ensino de ciências naturais, poderia contemplar discussões aprofundadas relativas aos fatores responsáveis pela crise ambiental, entre eles o consumo, oportunizando aos educandos a tomada de consciência concernentes à problemática ambiental.

Temos que reconhecer que, a partir da emergência do consumo como um dos fatores determinantes da crise, surgiu um novo ator social - o consumidor que se "quer" responsável. Esse consumidor tem um papel importante, na medida em que é capaz de "[...] modificar suas escolhas individuais e diárias de consumo, exercendo pressão sobre o sistema de produção" (PORTILHO, 2005, p. 34). Assim, propomo-nos a apreender as ideias sobre consumo e sustentabilidade em suas interrelações, junto aos alunos de Licenciatura em Ciências Naturais, do

\footnotetext{
3 Conhecida também com Eco-92, Cúpula da Terra, a Conferência das Nações Unidas sobre o Meio Ambiente e o Desenvolvimento foi uma conferência de chefes de Estados, realizada de 3 a 14 de junho de 1992, na cidade do Rio de janeiro, PARA debater os problemas ambientais.
} 
Campus Marajó-Breves, estado do Pará. Entendemos que as reflexões referentes às contribuições do ensino das ciências naturais para a promoção do consumo consciente são de fundamental importância para enriquecer o debate em curso sobre a questão ambiental.

\section{PEGADA ECOLÓGICA: UM INSTRUMENTO PARA DISCUTIR OS IMPACTOS DO CONSUMO}

Cotidianamente, entramos em contato com muitas informações veiculadas por diferentes meios de comunicação, relativas a novos produtos. Portanto, somos estimulados, sistematicamente, ao consumo. Como ressalta Sarreta (2007), raramente nos questionamos sobre os impactos desse consumo para o meio ambiente. Um instrumento interessante, em termos didáticos pedagógicos, para introduzir questões relacionadas ao consumo é a Pegada Ecológica.

Esse instrumento, segundo Cervi e Carvalho (2010), começou a ser utilizado a partir do lançamento do livro Our ecological footprint ${ }^{4}$, de autoria de Willian Rees e Mathis Wackernagel, no qual os autores propunham a Pegada Ecológica como ferramenta para medir o desenvolvimento sustentável. Esse método consiste basicamente de "[...] um índice de sustentabilidade que mede o impacto do homem sobre a Terra, um indicador da pressão exercida sobre o ambiente, e permite calcular a área de terreno produtivo necessária para sustentar o nosso estilo de vida" (CERVI; CARVALHO, 2010, p. 16).

Neste ponto, temos a destacar que o ensino de Ciências colabora para o rompimento da visão acrítica sobre o consumo. E, nesse sentido, uma das estratégias que pode ser utilizada para tanto é a abordagem temática, fundamentada na perspectiva Ciência, Tecnologia e Sociedade (CTS), certamente, por permitir a realização de

\footnotetext{
${ }^{4}$ Nossa pegada ecológica, tradução.
} 
conexões entre os conteúdos das disciplinas e as questões relacionadas ao consumo não sustentável. Além do mais,

Diante da complexidade e da rápida evolução do
conhecimento científico, pode parecer ambição
inalcançável tornar a formação científica um direito
universal, e desenvolver um currículo para as ciências na
educação básica, capaz de contribuir para o
enfrentamento de problemas da sociedade
contemporânea, como exclusão econômica,
individualismo consumista, desrespeito humano e
ameaça ambiental (MENEZES, 2009, p. 184).

Consideramos que, ao aliar temas socioambientais aos conteúdos das disciplinas, os professores podem realizar discussões sobre a inserção destes temas na sociedade, discutindo, ainda, as possibilidades produzidas pela ciência e pela tecnologia para a melhoria da qualidade de vida, contribuindo para o desenvolvimento de uma apreensão mais crítica da realidade. Portanto, ao discutir temas socioambientais em sala de aula, o professor estará aproximando o currículo escolar do contexto dos educandos, colaborando para a formação de cidadãos conscientes.

De acordo com Figueiredo, Almeida e César (2004), são as práticas em sala de aula que vão influenciar as perspectivas que os alunos têm, não só sobre o mundo, mas também acerca das questões relacionadas à sustentabilidade e à ciência. Para isso, é necessário o desenvolvimento de metodologias que promovam discussões, confronto com as pré-concepções e reflexões sobre as questões em discussão, de modo que se estabeleça uma abordagem eficaz acerca dos assuntos relacionados às questões socioambientais.

\section{PERCURSO METODOLÓGICO}

A pesquisa apresentada enquadrou-se na modalidade qualitativa. As informações foram apreendidas durante uma atividade complementar denominada "Educação Científica com enfoque CTS", 
do Curso de Licenciatura em Ciências Naturais, da Faculdade de Ciências Naturais, da Universidade Federal do Pará, Campus MarajóBreves, com a participação de 22 alunos. O formato da atividade configurou-se como um estudo de caso no ensino (SÁ; QUEIROZ, 2010), intitulado "A pegada ecológica: uma questão de sustentabilidade".

$\mathrm{Na}$ elaboração do estudo de caso, utilizamos o recurso da narrativa fictícia, contudo verossímil, cujo personagem lidava com a sedução do consumo. Os alunos foram estimulados a compreender as circunstâncias, os fatos, os valores e os contextos que permeavam a situação-problema. Para fins do presente trabalho, limitamo-nos a analisar um dos instrumentos de pesquisa, a "Carta Aberta à Sociedade", sobre a questão da sustentabilidade ambiental do planeta. A carta foi elaborada em sala de aula por duplas de alunos, como atividade final do estudo de caso.

A análise textual discursiva foi o recurso metodológico para apreender as ideias anunciadas pelos sujeitos de pesquisa. Segundo Moraes e Galiazzi (2007, p. 7), "[...] corresponde a uma metodologia de análise de dados e informações de natureza qualitativa com a finalidade de produzir novas compreensões sobre os fenômenos e discursos". De acordo ainda com Moraes e Galiazzi (2007), os textos submetidos à análise são denominados corpus, os quais representam as várias vozes que se manifestam sobre o fenômeno investigado.

\section{IDEIAS EM MOVIMENTO}

As cartas elaboradas foram lidas e posteriormente analisadas com o intuito de encontrar trechos que apontassem as inter-relações estabelecidas, pelos estudantes, entre consumo e sustentabilidade. As análises nos permitiram constatar que as ideias apresentadas nas cartas centravam-se, basicamente, em dois aspectos, a saber: a situação do planeta e as contribuições do consumo para a configuração da crise socioambiental. Desse modo, organizamos as ideias em duas 
categorias, quais sejam: (a) situação do planeta e (b) Consumo: "O vilão".

\section{Situação do Planeta}

Todas as cartas iniciavam apresentando a condição atual do nosso planeta, ressaltando, sempre, a atuação desastrosa da espécie humana, como podemos constatar nos trechos de algumas cartas, a saber:

Carta 2: Estamos diante de uma situação que se agrava cada vez mais por causa do nosso comportamento. Nós não sabemos cuidar do meio ambiente e cometemos ações que prejudicam demais 0 meio em que vivemos;

Carta 3: [...] o cenário atual é preocupante, pois o Homem em sua relação com o meio ambiente parece ter uma única finalidade: retirar do meio envolvente todos os recursos possíveis para atender seus objetivos;

Carta 4: O nosso modo de vida, pautado no uso exacerbado dos recursos naturais, vem impactando o meio ambiente natural e social $[\ldots]$;

Carta 7: [...] o meio ambiente está sofrendo com o nosso descaso e irresponsabilidade. [...] pessoas degradam, desmatam, polvem sem se preocupar com as consequências que isso provoca.

Quanto a isso, podemos destacar que esse cenário foi se configurando nas últimas décadas do século XX, como resultado de um modelo de produção pautado no uso irracional dos recursos naturais, o que culminou nos primeiros sinais da degradação ambiental, notadamente como sintoma de uma crise de civilização.

Ademais, essa crise está fundamentada no modelo de modernidade, regido pelo predomínio do desenvolvimento da razão tecnológica (racionalidade instrumental) sobre a organização da natureza (racionalidade reflexiva) (LEFF, 2001; YUS, 2007). Essa crise, "[...] é antes de tudo uma crise antrópica, vale dizer, de uma crise derivada de atividades humanas" (SOFFIATI, 2005, p. 44). No entanto, é válido ressaltar que 
Ocorreram crises planetárias não-antrópicas na história da terra e crises antrópicas não-planetárias na história da humanidade; entrementes, é a primeira vez, [...] que se constituiu uma crise ambiental oriunda das atividades exercidas por uma só espécie - no caso, a nossa - que assume um caráter global (SOFFIATI, 2005, p. 47).

Precisamos, então, repensar nosso modo de vida, direcionando nossas ações para um caminho mais racional e sustentável, pois dependemos dos recursos naturais para a manutenção da nossa qualidade de vida. É importante destacar que as atitudes individuais são importantes, mas necessitamos de um trabalho coletivo, no qual todos se empenhem para garantir um futuro viável para as próximas gerações.

\section{Consumo: o "vilão"}

Nos trechos apresentados a seguir, constatamos que os alunos conseguem estabelecer inter-relações entre consumo e sustentabilidade, na medida em que declaram a necessidade de modificarmos o nosso modo de vida.

Carta 1: Temos que urgentemente mudar o nosso estilo de vida, temos que economizar e consumir apenas o que for necessário para a manutenção de nossas vidas;

Carta 4: Cada vez mais é maior o número de pessoas que consomem produtos em excesso sem se preocupar com as consequências que esse hábito pode trazer para o meio ambiente.

O consumo aparece, então, como protagonista, que ganha destaque por ser o "vilão", em um cenário marcado por sérios problemas socioambientais. Por reconhecerem isso, os autores das cartas apresentam a pegada ecológica como uma alternativa para repensarmos o consumo, como podemos verificar nos seguintes trechos: 
Carta 3: Temos que contribuir de forma positiva diminuindo nossa pegada ecológica e reavaliando nosso estilo de vida para que não haja a degradação total dos recursos naturais;

Carta 7: A pegada ecológica é uma realidade que precisa ser mais entendida pela sociedade em geral. [...] se nós consumirmos muita carne de boi, consequentemente teríamos que ter mais áreas de pastos, ocasionado mais desmatamentos [...], a pegada ecológica é justamente para nós pensarmos em nossos conceitos e tentar melhorar os nossos hábitos;

Carta 10: [...] a nossa sociedade precisa aprender um pouco mais sobre o desenvolvimento sustentável, a pegada ecológica e outras medidas que venham ajudar uma interação mais responsável dos seres humanos com o meio ambiente.

Nesse contexto, podemos referir que a Agenda 21 Global aborda o tema "Mudança de Padrões de Consumo", destacando que a situação atual do nosso planeta está diretamente relacionada aos padrões insustentáveis de produção e de consumo (CONFERÊNCIA, 1997). A mudança nos padrões de consumo exige estratégias centradas na demanda, no atendimento das necessidades básicas dos pobres, na redução do desperdício e do uso de recursos finitos no processo de produção (CONFERÊNCIA, 1997), ou seja, pauta-se na adoção de um modo de vida sustentável.

Além disso, o referido documento alerta também para a necessidade de uma transformação na forma de consumir e de produzir. Nesse sentido, propõe que os governos estimulem consumidores a acessarem informações sobre as consequências das opções e dos comportamentos de consumo, estimulando, assim, escolhas por produtos ambientalmente saudáveis (CONFERÊNCIA, 1997).

Um dos caminhos para a efetivação dessas ações é a educação, uma vez que ela é considerada instrumento eficaz no processo de construção de um mundo sustentável. Isso porque "[...] nos habilita como indivíduos e como comunidades a compreendermos a nós mesmos e aos outros e as nossas ligações com o meio ambiente social e 
natural de modo mais amplo" (UNESCO, 2005, p. 43). Entretanto, encontramos apenas em duas cartas referências à educação, quais sejam:

Carta 9: [...] todos os cidadãos devem ser constantemente ensinados e chamados a adoção de práticas que garantam a sustentabilidade de todos os seus atos e ações, entre elas: destinar corretamente os resíduos domésticos, a presenação das matas, etc. [...] o mais importante de tudo é educar e fazer com que o cidadão entenda que tudo o que ele faz ou fará pode gerar impactos no meio ambiente;

Carta 10: [...] a melhor forma para a nossa sociedade aprender ações de proteção ao meio ambiente é através da educação.

A educação é, sem dúvida, um dos caminhos para a promoção do desenvolvimento sustentável. Por isso, é de fundamental importância incorporar ao processo educativo discussões sobre as causas e as consequências da crise ambiental, ressaltando a necessidade de modificarmos o nosso modo de vida. Esperávamos encontrar um maior número de referências à educação, por se tratar de alunos de um curso de licenciatura, entretanto, não foi o observado, infelizmente.

Consideramos que a educação não ganhou o destaque esperado, pois apesar da vigência da crise ambiental, ainda se fala pouco nas salas de aula de questões relacionadas à sustentabilidade. Acreditamos que os professores deveriam, independentemente do nível em que atuam, na educação básica ou superior, transformar a sala de aula em espaço de trocas reais, no qual alunos e professores são capazes de dialogar sobre o mesmo mundo, um mundo mais próximo e mais condizente com a realidade que se pretende desvelar (DELIZOICOV; ANGOTTI; PERNAMBUCO, 2009).

\section{CONSIDERAÇÕES FINAIS}

Nossa espécie vem ao longo das gerações solidificando um modelo de relacionamento com a natureza assentado na exploração irracional dos recursos naturais. E, a causa principal reside na 
elaboração de novos produtos, com a finalidade de estimular o consumo. Todos os dias, novos produtos são lançados no mercado e a tendência é que sejam consumidos rapidamente.

Ao desenvolver o estudo de caso "Pegada Ecológica: uma questão de sustentabilidade", oportunizamos aos estudantes refletirem sobre o nosso atual estilo de vida, ensejando ainda a reflexão sobre a necessidade de adotarmos um novo modo de relacionamento com a natureza. Consideramos que isso só foi possível porque adotamos o enfoque CTS. O enfoque CTS favorece o envolvimento e a participação dos alunos nas discussões, na busca de solução, na tomada de consciência e na tomada de decisão informada, quando necessária.

Ao término do estudo de caso, notamos que os alunos conseguiram perceber as relações existentes entre as questões do consumo e a necessidade de construção de um modo de vida pautado no princípio da sustentabilidade ambiental. Ressaltamos, também, que os alunos conheceram, a partir do estudo de caso, um instrumento fundamental no processo de reflexão sobre o nosso estilo de vida: a pegada ecológica. Ao calcular suas pegadas, os alunos ficavam surpresos com a quantidade de recursos necessários para a manutenção dos seus modos de vida.

Despertou nossa atenção a diminuta indicação da educação enquanto caminho viável na construção de um mundo sustentável. Acreditamos, então, que urge repensar a educação, em especial o ensino de ciências, pois o mesmo também possui a responsabilidade de viabilizar uma melhor leitura de mundo.

Para que isso ocorra, os professores devem estar preparados para, de posse dos conhecimentos das questões colocadas pela crise ambiental, serem capazes de motivar discussões em sala de aula que possibilitem o enfoque para além dos conteúdos das disciplinas, incorporando as leituras do campo social, ambiental, político, econômico e ético, notadamente as questões relacionadas às implicações da ciência e da tecnologia na sociedade. 


\section{REFERÊNCIAS}

AMARAL, M. T. do. A dimensão ambiental na cultura educacional brasileira. Revista Brasileira de Estudos Pedagógicos. Brasília, v. 88, n. 218. p.107-121. 2005.

BARBIER, R. A pesquisa-ação. Brasília: Livel Livro, 2007.

CERVI, J. L.; CARVALHO, P. G. M. de. A Pegada Ecológica do Município do Rio de Janeiro. Revista Iberoamericana de Economía Ecológica, España, v. 15, p. 15-29, 2010.

CONFERÊNCIA DAS NAÇÕES UNIDAS SOBRE MEIO AMBIENTE E DESENVOLVIMENTO (Rio de Janeiro, 1992). 2. ed. Brasília, DF: Senado Federal, Subsecretaria de Edições Técnicas, 1997.

DELIZOICOV, D.; ANGOTTI, J. A.; PERNAMBUCO, M. M. Ensino de Ciências: fundamentos e métodos. 3. ed. São Paulo: Cortez, 2009.

FIGUEIREDO, O.; ALMEIDA, P.; CÉSAR, M. O papel das metaciências na promoção da educação para o desenvolvimento sustentável. Revista Eletrônica de Enseñanza de las Ciencias, España, v. 3, n. 3, p. 320-338, 2004.

LEFF, E. Epistemologia ambiental. 2. ed. São Paulo: Cortez, 2002.

LEIS, H. R. Ambientalismo: um projeto realista-utópico para a política mundial. In: VIOLA, E. J. Meio ambiente, desenvolvimento e cidadania: desafios para as Ciências Sociais. 3. ed. São Paulo: Cortez, 2001. p. 1543.

MENEZES, L. C. de. Cultura científica na sociedade pós-industrial. In: WERTHEIN, J. CUNHA, C. da (Org.). Ensino de Ciências e desenvolvimento: o que pensam os cientistas. 2. ed. Brasília, DF: UNESCO, Instituto Sangari, 2009. p. 181-186.

MORAES, R.; GALIAZZI, M. do C. Análise textual discursiva. ljuí: Unijuí, 2007.

PORTILHO, F. Sustentabilidade ambiental, consumo e cidadania. São Paulo: Cortez, 2005.

SÁ, L. P.; QUEIROZ, S. L. Estudo de casos no ensino de química. Campinas, São Paulo: Editora Átomo, 2010. 
SACHS, I. O desafio do meio ambiente. In: SACHS, I.; VIEIRA, P.F (Org). Rumo à ecossocioeconomia: teoria e prática do desenvolvimento. São Paulo, 2007. p. 201-246.

SARRETA, C. R. L. Meio ambiente e consumo sustentável: direitos e deveres do consumidor. Passo Fundo, RS: Ed. Universidade de Passo Fundo, 2007.

SOFFIATI, A. Fundamentos Filosóficos e Históricos para o exercício da ecocidadania e da ecoeducação. In: LOUREIRO, C. F. B.; LAYRARGUES, P. P.; CASTRO, R. S. de. (Org.) Educação Ambiental: repensando o espaço da cidadania. 3. ed. São Paulo: Cortez, 2005. p. 23-67.

YUS, M. Á. M. Pegadogía para la sostenibilidad basada em recuperación de três vínculos: vital, humano y natural. Education Siglo XXI, España, n. 25, p. 167-186, 2007.

ZACARIAS, R. "Sociedade de Consumo", ideologia do consumo e as iniqüidades socioambientais dos atuais padrões de produção e consumo. In: LOUREIRO, Carlos Frederico Bernardo; LAYRARGUES, P. P.; CASTRO, R. S. (Org.). Repensar a Educação Ambiental: um olhar crítico. São Paulo: Cortez, 2009. p. 119 - 139. 


\title{
MEDIAÇÕES TEATRAIS NO ENSINO DO CORPO HUMANO: CONTRIBUIÇÕES PARA A FORMAÇÃO DE PROFESSORES E O FAZER DOCENTE DIFERENCIADO 5
}

\author{
Erllon Rodolfo Viegas Barata \\ Cássia Nunes Leão \\ Renan Ferreira Freitas \\ Nívia Magalhães da Silva Freitas \\ Darlene Teixeira Ferreira \\ Nadia Magalhães da Silva Freitas
}

\section{INTRODUÇÃO}

O corpo humano tem se apresentado como objeto de conhecimento de diversos campos, com uma significativa abrangência de apreensões (MILSTEIN; MENDES, 2010). Cabe destacar que o ensino de Ciências tem valorizado a dimensão biológica do corpo humano (TRIVELATO, 2005), dado que, historicamente, "[...] o corpo foi interpretado sob uma ótica dualista, mecanicista e biologicista" (MACHADO; BARRETO, 2013, p. 1). Nesse sentido, o "[...] corpo humano [...] recebe uma educação que o considera apenas em seu aspecto mecânico, sem vontade própria [...], o qual é explicado através da mera reação a estímulos externos, sem qualquer relação com a subjetividade" (MENDES; NÓBREGA, 2004, p.125).

A educação, nos tempos atuais, ainda é influenciada pelo pensamento cartesiano. É nesse contexto que se observa a abordagem ao corpo, por exemplo, dividido em partes: cabeça, tronco e membros (RAMOS; FONSECA: GALIETA, 2018). A compreensão do corpo humano como uma mera máquina o destitui de toda a sua expressividade, individualidade e singularidade, aspectos fundamentais no (re)conhecimento dos seres humanos.

O corpo humano é carregado de multiplicidades, ele "[...] é ao mesmo tempo social, psicológico, biológico e transcendente" (RIOS,

\footnotetext{
${ }^{5}$ Publicado originalmente no XII Encontro Nacional de Pesquisa em Educação em Ciências, em 2019, revisado e atualizado.
} 
2015, p. 2). Raras são as abordagens ao corpo humano "[...] como aquela que abrange o corpo para além de perspectivas puramente biológicas e fisiológicas [...]" (VIANNAY; SELLES, 2016, p. 3095), o que contribuiria para uma visão do corpo humano sob a perspectiva de outras dimensões que o constituem - "objeto" multidimensional.

Nesse sentido, o presente trabalho objetivou compreender em que termos uma experiência formativa, tendo o teatro como materialidade mediadora do aprender e do ensinar o tema corpo humano e saúde na sua dimensão social, contribuiu para pensar o teatro como outro modo (diferenciado) de formação e do fazer docente. Evocamos a arte, ao reconhecê-la como uma "[...] dimensão sensível do humano [...] [que] colabora para inserção do ser humano no mundo com qualidade social [...]" (FREITAS, 2017, p. 28).

\section{ABORDAGEM METODOLÓGICA}

A investigação inseriu-se no campo qualitativo (MINAYO, 2016). Adotamos a pesquisa-formação que, nos termos de Josso (2010), compreende que os processos formativos envolvem uma dimensão de conhecimento e quem dele participa é capaz de narrá-los, tanto como construção individual como coletiva, contribuindo para constituição de aprendizagens interpretativas e reflexivas.

A pesquisa se deu no contexto do desenvolvimento do tema "Alfabetização e Letramento em Ciências e Matemática I - Corpo Humano e Saúde" (a proposta curricular do Curso, em que a pesquisa ocorreu, está organizada por eixos temáticos, temas e assuntos, numa perspectiva interdisciplinar), do Curso de Licenciatura Integrada em Ciências, Matemática e Linguagens, da Universidade Federal do Pará.

Tratamos o tema "corpo humano e saúde" também sob a perspectiva biológica. Contudo, para escapar do viés unicamente biologicista dos conteúdos, experimentamos a produção de 
conhecimentos, a partir da materialidade mediadora do teatro, mediante a produção de esquetes teatrais, envolvendo quatro eixos: como e quando nasce o corpo, o corpo crescendo, o corpo adulto e o corpo idoso, privilegiando aspectos relacionados a outros campos, a saber: o social.

Trazemos para este artigo a análise das entrevistas, um dos instrumentos de coleta de dados, cujos conteúdos foram submetidos à análise interpretativa (CRESWELL, 2014), buscando as respostas para atender os objetivos da pesquisa, conforme apresentado anteriormente. Cabe destacar, neste ponto, que os discentes participantes da pesquisa assinaram o Termo de Consentimento Livre e Esclarecido (TCLE). Nele constavam objetivos, metodologia, benefícios e possíveis riscos da pesquisa para os entrevistados. Também realizamos os devidos esclarecimentos sobre dúvidas da pesquisa. Os licenciandos foram identificados, neste texto, pelos sobrenomes, acrescido das iniciais dos nomes, com objetivo de resguardar suas identidades.

\section{O TEATRO ENTRA EM CENA NA FORMAÇÃO DOS PROFESSORES}

A arte não deve ser considerada um fim em si mesmo, mas, ao contrário, um meio para proporcionar aprendizagens distintas. A Ciência e a Arte (representada aqui pelo teatro) "[...] são espaços de possibilidades, investigação, autoria, autonomia, construção de conhecimentos e subjetividade" (KLISYS, 2010, p. 13).

Nesse sentido, as experiências estéticas evidenciadas no processo formativo mostraram-se bastante diversificadas, trazendo preocupações contemporâneas do campo da saúde, vinculadas aos aspectos sociais, a saber: obesidade, frente aos hábitos e ao consumo em tempos de modernidade; violência contra a mulher, incluindo aqui violência obstétrica; violência contra o idoso; tabagismo e o convívio familiar; gravidez na adolescência e conflitos familiares, entre outros. 
Das nossas análises, e para fins deste trabalho, apresentamos nas subseções que se seguem, dois aspectos destacados nas vivências estéticas: aqueles que engendraram reflexões sobre 0 processo formativo e as possibilidades do fazer docente diferenciado no processo de ensino e de aprendizagem em sala de aula.

\section{O teatro para refletir o processo de formação de professores}

Na nossa compreensão, a formação de professores, para além de aquisição de saberes prontos e acabados, e frente às intensas mudanças vivenciadas atualmente na sociedade, deve se constituir conquista de aprendizagens, no sentido de criar caminhos à reflexão dos processos/atividades formativos. Nesse contexto, trazemos algumas das manifestações dos licenciandos quanto às contribuições das experiências teatrais para a formação de professores. Vejamos:

[...] a atividade que desenvolvemos [esquetes teatrais] [...] nos mostrou uma perspectiva sobre o ensino de ciências envolvendo o corpo humano que ainda não tinha conhecimento e nem imaginava que seria possível ocorrer tão naturalmente (QUEIROZ, D. P. R. M);

[...] O teatro é algo que eu já havia feito [...], porém a interação disso em uma sala de aula [...] é totalmente diferente [...]. Em termos de formação, pude perceber o quanto é importante aprender novas vertentes para ensinar (CARVALHO, T. B);

[...] foram processos surpreendentes [...] contribuiu muito para minha formação [...] são formas de trabalhar em sala de aula com o lúdico e relacionado ao letramento científico na educação [...] é de suma importância para que nós professores aprendêssemos várias formas de trabalhar na sala de aula [...]. (FRANCO, D. S. A.).

Os excertos destacados nos fazem pensar que, provavelmente, muitos discentes, e acreditamos que até mesmo professores, idealizam que o único lugar possível de ocorrer uma manifestação teatral seja em um Teatro, propriamente dito. A sala de aula parece ser o último lugar a se pensar para desenvolver práticas ligadas ao teatro para ensinar 
determinado conteúdo, quer seja conceitual, procedimental ou atitudinal.

Para Ta Gein (2014), muitos professores podem afirmar que, por não serem artistas, não têm condições de trazer a arte para sala de aula. Mas, entendemos, como Figueiredo (2015, p. 141), que "[...] $\circ$ professor artista aqui é a capacidade de o professor ser criador no espaço da sala de aula [...]". Daí a importância de oportunizarmos momentos formativos, que envolvam o teatro, ainda no âmbito da formação inicial, para que os licenciandos experimentem outras formas de ensinar.

A declaração do discente, a seguir, expressa uma questão interessante e importante ao ensino de Ciências:

[...] a prática teatral desenvolvida [...] foi de suma importância para minha formação [...] o teatro nos dá essa oportunidade [...] falar sobre o cotidiano [...] (LUZ, V.S).

É fato que muito se tem falado da importância de associar os conteúdos escolares à realidade dos alunos, na perspectiva de proporcionar um ensino que tenha um verdadeiro significado, diferentemente do ensino puramente memorístico (TA GEIN, 2014). Corroborando com o licenciando supracitado, podemos referir que "[...] o teatro possibilita um ensino mais dinâmico e motivador [...], especialmente com a potencialidade de aproximar os conteúdos escolares de situações cotidianas dos alunos" (FREITAS, 2017, p. 135).

Segundo um dos licenciandos, apesar de seu pouco contato com o campo teatral, a vivência teatral trouxe um novo sentimento, a saber:

[...] as minhas experiências com teatro eram quase nada, mesmo com essa deficiência de conhecimento foi uma experiência na qual me senti muito encorajado e confiante (ALMEIDA, C. G).

Podemos depreender que as atividades artísticas, especialmente o teatro, precisam ser apresentadas aos licenciandos de maneira que eles se sintam à vontade em participar e, futuramente, desenvolver tais 
experiências na sua sala de aula, notadamente ao considerarmos o seguinte: o que a tradição aprisiona, a arte liberta (TA GEIN, 2014).

\section{O teatro como materialidade mediadora para o fazer docente diferenciado}

A arte (teatro) constitui-se uma das linguagens do ser humano. Assim, é importante que ela seja considerada no ambiente da sala de aula, de modo que possa contribuir para os processos de ensino e de aprendizagem, na perspectiva de um fazer docente diferenciado. Nesse contexto, temos as observações de um licenciando, quais sejam:

[...] há um grande desafio em associar a prática do ensino de ciências com a arte, mas o envolvimento com essa prática [...] é extremamente recompensador [...] apresentação artística proporciona uma grande possibilidade de vincular o conteúdo didático [...] de uma maneira muito mais interessante para os alunos (QUEIROZ, D. P. R).

Entendemos que é importante encaminhar as aprendizagens na compreensão de que existem outras possibilidades que comunicam conteúdos, desenvolvem habilidades, refletem sobre atitudes e expressam sentimentos (OCHÔA; SCHELBAUER, 2013). Tais aspectos foram percebidos igualmente por outro licenciando, a saber:

[...] propusemos o teatro para expor uma forma humorada e também concreta para ensinar novos hábitos [...] diante de uma vida sedentária [...] com certeza trabalharia com teatro com meus alunos [...] com o teatro podemos adquirir conhecimento de forma criativa (SANTOS, R. W).

Também podemos referir que experiências no campo artístico possibilitam a escolha de percursos importantes para o processo de ensino e de aprendizagem, na medida em que a arte desenvolve o sentir, o olhar, o inovar e o criar alternativas para melhor entender o mundo (SPONTON, 2014). Nesse âmbito, temos as seguintes manifestações: 
[...] gostei bastante dessa inovação de abordar o ensino de ciências fazendo uso das práticas teatrais [...] é uma forma de ensinar conteúdos de forma dinâmica, onde o aluno pode envolver-se mais e com isso aprender melhor [...] julgo isso importante (CORRÊA, R. B);

[...] O teatro, uma prática inovadora, também é pouco adotada na sala de aula [...] trás [...] a possibilidade do aluno se enxergar por outro ângulo, representando um papel, atuando num contexto, facilitando o processo de ensino e de aprendizagem [...] (SANTOS, H. N).

Podemos ponderar, nesse contexto, que a relação Ciência e Arte (teatro) pode promover articulações que contribuem para o processo de ensino e de aprendizagem dos alunos, inserindo-se como aspecto diferenciado na prática docente, no sentido de praticar "[...] um ensino que estimule a imaginação, a criatividade, a sensibilidade e a intuição" (FERREIRA, 2010, p. 3).

\section{CONSIDERAÇÕES FINAIS}

A formação de professores que ensinam Ciências enfrenta 0 desafio de favorecer uma apreensão efetiva e significativa dos aspectos que pautam, por exemplo, o ensino do corpo, no sentido de sua renovação. Assim, buscamos na materialidade mediadora do teatro experimentar a abordagem do corpo humano para além de suas partes. Propusemos aos discentes a elaboração de esquetes teatrais para tratar o tema corpo humano com ênfase na sua dimensão social.

Ao empreender tal processo, fizemo-lo com intencionalidade pedagógica de possibilitar aos licenciandos que estes aprendessem vivenciando, produzindo. Nesse sentido, colaboramos para a formação ambiental, notadamente na consideração do teatro como um dos elementos importantes à prática docente.

Nesse processo, registramos a importância atribuída pelos licenciandos à experiência sensível propiciada pelo teatro, tanto para a 
formação como para os processos de ensino e de aprendizagem de seus futuros alunos, na perspectiva de um fazer docente diferenciado.

\section{REFERÊNCIAS}

CRESWELL, J. W. Investigação qualitativa e projeto de pesquisa: escolhendo entre cinco abordagens. Tradução: Sandra Mallmann da Rosa. 3 ed. Porto Alegre: Penso, 2014.

FERREIRA, F. R. Ciência e arte: investigações sobre identidades, diferenças e diálogos. Educação e Pesquisa, São Paulo, v. 36, n. 1, p. 261-280, 2010.

FIGUEIREDO, R. C. de. A aprendizagem da docência em teatro através da participação em um projeto de Extensão Universitária. Art Research Journal, Rio Grande do Norte, v. 2, n. 2, p. 138-153, 2015.

FREITAS, N. M. S. Ensino de ciências e práticas teatrais: formação de professores para os anos escolares iniciais. 2017. 210 f. Tese (Doutorado em Educação em Ciências e Matemáticas. Programa de PósGraduação em Educação em Ciências e Matemáticas, Universidade Federal do Pará. Pará. 2017.

JOSSO, M. C. Experiências de vida e formação. $2^{a}$ ed. Natal: EDUFRN, 2010.

KLISYS, A. Ciência, arte e jogo. São Paulo: Peirópolis, 2010.

MACHADO, E. F. C, BARRETO, A. B. A concepção de corpo abordada nos livros didáticos de biologia do programa nacional do livro didático (PNDL) 2012-2014. In: Seminário do Programa de Pós-Graduação em Educação para Ciências e Matemática, 1; Semana de Licenciatura, 10. Jataí - Goiás, 26 a 29 de junho de 2013. Disponível em: http://www.jatai.ifg.edu.br/semlic/seer/index.php/anais/article/view/300 /pdf_51. Acesso em: 5 jan. 2018.

MENDES, M. I. B. de S.; NÓBREGA, T. P. Corpo, natureza e cultura: contribuições para a educação. Revista Brasileira de Educação, Rio de Janeiro, n. 27, p. 125-137, 2004.

MILSTEIN, D.; MENDES, H. Escola, corpo e cotidiano escolar. São Paulo: Cortez, 2010. 
MINAYO, M. C. de. S. Trabalho de campo: contexto de observação, interação e descoberta. In: MINAYO, M. C. de. S. (Org.) Pesquisa social: teoria, método e criatividade. Petrópolis, RJ: Vozes, 2016. p. 56-71. (Série Manuais Acadêmicos).

OCHÔA, P. C. A.; SCHELBAUER, A. R. Teatro na formação de professores das séries iniciais do ensino fundamental. Seminário de Pesquisa do PPE. Maringá, p. 1-19, 2013. Anais eletrônicos ... Disponível em: http://www.ppe.vem.br/publicacoes/seminario_ppe_2013/trabahos/co_ 03/85.pdf. Acesso em: 21 set. 2018.

RAMOS, K. C. A. B.; FONSECA, L. C. S.; GALIETA, T. Visões sobre o ser humano e as práticas docentes no ensino de ciências e biologia. Revista Exitus, Santarém, Pará, v. 8, n. 1, p. 305-331, 2018.

RIOS, F. T. A. A importância do corpo no processo de ensino e aprendizagem. Evidência, Araxá, v. 11, n. 11, p. 49-58, 2015.

SPONTON, M. H. C. Arte: espaço de investigação, construção e humanização. In: PHILIPPI JR., A.; PELICIONI, M. C. F. Educação ambiental e sustentabilidade. São Paulo: Manole, 2014. p. 550-578.

TA GEIN, E. A. Ambientar arte na educação. In: PHILIPPI JR., A.; PELICIONI, M. C. F. Educação ambiental e sustentabilidade. São Paulo: Manole, 2014. p. 539-549.

TRIVELATO, S. Que corpo/ser humano habita nossas escolas? In MARANDINO, M. SELLES, S. E.; FERREIRA M. S. Ensino de Biologia: histórias e práticas em diferentes espaços educativos. 1. ed. São Paulo: Cortez Editora, 2005. v. 1.

VIANNAY, C. V. C.; SELLES, S. L. E. Produção acadêmica sobre o ensino do corpo humano nas disciplinas escolares ciências e biologia. Revista SBENBIO, São Paulo, n. 9, p. 3897-3907, 2016. 


\title{
"MÚSICA NO VARAL": A EDUCAÇÃO PARA A SUSTENTABILIDADE NA/PARA A AMAZÔNIA'
}

\author{
Sebastião Nogueira da Fonseca Neto \\ Nívia Magalhães da Silva Freitas \\ Paulo Vilhena da Silva \\ Nádia Magalhães da Silva Freitas
}

\section{INTRODUÇÃO}

A Amazônia constitui-se região de natureza singular, ao considerarmos sua sociobiodiversidade. Entretanto, tem sido despojada do seu patrimônio socioambiental, o que tem gerando cenários de conflitos na região, a despeito de propostas de desenvolvimento da/para região que se inserem na perspectiva do desenvolvimento sustentável. Esforços para garantir o desenvolvimento, o uso racional de recursos e a sensibilização social têm sido empreendidos na Amazônia (BECKER, 2009; GONÇALVES, 2019), mas o capital tem sobrepujado tais ações, e o que vivenciamos é a pilhagem da Amazônia.

Atualmente, a Amazônia tem se constituído preocupação global, notadamente quando se pensa na contribuição da região para as mudanças climáticas, a exploração dos recursos genéticos, o sequestro de carbono, entre outros (MELLO, 2006). Nesse contexto, muitas ações/investimentos têm se voltado para atividades de conservação e de concretização de uma economia local, fundamentadas na perspectiva da sustentabilidade. Por outro lado, convive-se, simultaneamente, com o desenvolvimento de grandes projetos na Amazônia, cujas demandas, na maioria das vezes, são forâneas. Tais projetos têm acarretado grandes passivos socioambientais (PINTO, 2002).

6 Publicado originalmente no Congreso Iberoamericano de Ciencia, Tecnología, Innovación y Educación, em 2014, revisado e atualizado. 
É nesse contexto que a Amazônia precisa ser problematizada em seus múltiplos campos. A educação é um deles, mas há que ser permeada pela perspectiva da sustentabilidade. Por sua vez, faz-se necessário também considerar as relações Ciência, Tecnologia e Sociedade (CTS), em atenção ao que foi ressaltado por Bazzo (2010), ou seja, os eventos que conformam a crise socioambiental têm relação intrínseca com o entendimento de que a ciência e a tecnologia são, no conjunto, força que impulsiona o progresso e o desenvolvimento; entretanto, pouco se considera sobre suas implicações sociais, ambientais, culturais, políticas e éticas.

Dessa forma, o presente trabalho buscou apreender, a partir de atividades desenvolvidas com licenciandos, os aspectos críticos do desenvolvimento, especialmente no que se refere aos contextos de insustentabilidade, a despeito de todo um discurso de desenvolvimento sustentável na/para a Amazônia, e as implicações das relações CTS presentes no processo de desenvolvimento da região.

\section{PROBLEMATIZANDO O ENSINO DE CIÊNCIAS}

É cada vez mais difícil aliar conhecimento, vivência e aplicação do que os alunos estudam nas escolas. Segundo Trivelato (2000), estamos em uma época em que a desmotivação está presente entre alunos e professores: os primeiros não veem "aplicabilidade" dos conhecimentos que os docentes tentam thes ensinar, o que dificulta $o$ interesse e a apreensão dos conteúdos postos nos currículos escolares; já os professores, ressentem-se pela falta de motivação dos alunos, o que, aliado aos "ambientes indisciplinados" das escolas, resulta na perda de uma parte relevante do trabalho docente, a saber: a motivação pelo ensinar.

A questão que se coloca para esses discentes é o aparente hiato que existe entre as informações que recebem e ficam disponíveis em diversos meios de comunicação e nas redes sociais, por exemplo, e o Sumário - 
sólido conhecimento existente no que diz respeito a uma dada temática. Agregado ao diagnóstico de Trivelato (2000), no que tange à desmotivação de alunos, causada pela não instrumentalização do conhecimento, há de se considerar também os métodos e as técnicas pensados para o ensino de Ciências.

Nesse sentido, percebe-se que a formação de professores tem o desafio de superar o que se denomina de sociedade da capacitação, cuja crítica pauta-se na formação alijada das concepções e formações históricas. Sobre a denominação, a autora escreve:

[...] a sociedade da capacitação está menos interessada no que já se sabe e dá mais atenção ao quanto se é capaz de aprender. O investimento, então, é deslocado do que já se sabe para aquilo em que se pode transformar. A produção da subjetividade em tal sociedade é marcada pelo curto prazo, pela flexibilidade, pela informação e pelas incertezas advindas da cultura do novo capitalismo, contaminando, inclusive, outras esferas da vida. Ao mesmo tempo que a sociedade da capacitação engendra modos de controlar, ela se estende e penetra as instituições de ensino, afetando diretamente a aprendizagem de adultos e a formação de professores (DIAS, 2011, p. 131).

Percebe-se que, segundo a autora, os padrões atuais de conhecimento estão ligados a uma determinada visão de mundo, que desconsidera as variadas formas de saberes, o que não pode ser considerado algo bom quando pensamos na diversidade de saberes que tem emergido neste contexto (um exemplo desse fenômeno no campo da educação matemática é a etnomatemática, campo de pesquisa que estuda a aprendizagem matemática por métodos não formais; saberes tradicionais das sociedades ribeirinhas, entre outros). No entanto, deve ser considerado também que a flexibilização de tal conhecimento pode gerar impacto positivo no processo formativo dos profissionais que irão atuar na divulgação do conhecimento formal, escolar e/ou universitário (DIAS, 2011). 
Disso resulta que o conhecimento, que deve ser socialmente construído, validado e divulgado, encontra hoje na formação de professores obstáculos quanto ao desenvolvimento da habilidade de construir argumentos lógicos e articulados à realidade e, ainda, uma prática que busque incentivar esta construção, o que poderia auxiliar o aluno, não apenas durante sua vida escolar, mas também na sua formação cidadã (RAMOS, 2004). Tal exercício de cidadania é necessário, pois é ele que "[...] instrumentaliza a pessoa para uma participação política" (DEMO, 1998, p. 66) e tem por função "[...] desenvolver a racionalidade e capacitar futuros cidadãos a terem uma participação ativa e significativa no processo democrático e de tomada de decisão" (TRIVELATO, 2000, p. 47). A participação política e a tomada de decisão darão real sentido à palavra democracia, pois os alunos saberão o porquê de suas escolhas e poderão participar, ativamente, no processo de construção da realidade social.

\section{TENDÊNCIAS EM CTS: UMA VISÃO PRELIMINAR}

A abordagem ou enfoque Ciência, Tecnologia e Sociedade (CTS) não surgiu no ensino de ciências. O termo CTS foi primeiro veiculado em um movimento surgido, segundo Auler e Bazzo (2001), entre 1960 e1970, chamado de "movimento CTS". Tal movimento procurava efetivar o que Luján Lópes et al. (1996) denominava de "quebra do belo contrato social para ciência e tecnologia", referindose ao modo como a abordagem CTS rompe com a ideia positivista de neutralidade e objetividade da ciência em relação ao objeto de análise; neste caso, a própria ciência e tecnologia. Em seu lugar, o referido autor propõe uma análise crítica da real influência da ciência e da tecnologia na sociedade.

Auler e Bazzo (2001) citam duas obras do ano de 1962 que influenciaram, de certa forma, o movimento CTS. A primeira delas é a famosa obra "A Estrutura das Revoluções Científicas", do físico 
estadunidense Thomas Kunn (KUHN, 1998), na qual o autor trata da epistemologia da ciência, fazendo análise das transformações no âmbito das comunidades científicas. E, por meio dessa análise, busca-se descrever os processos, por intermédio dos quais as transformações acontecem. Nessa obra, o autor desmistifica o fazer científico "puro e imaculado" e propõe que a ciência não está isenta de sofrer influências das questões e dos interesses sociais. Tal visão encontra ainda hoje espaço no campo acadêmico, conquanto a própria ciência é sempre alvo de novas investigações e, por sua vez, o conhecimento na área da educação não está excluído desse processo (KUNH, 2006).

A segunda obra de grande influência, segundo Auler e Bazzo (2001), é "Primavera Silenciosa", da bióloga e zoóloga estadunidense Rachel Carson (CARSON, 2010), que já obtivera reconhecimento em outras áreas da história natural. A publicação da autora traz à discussão o problema do uso de pesticidas e da polvição. À obra é creditada o marco do surgimento do movimento ambientalista (AULER; BAZZO, 2001).

No entanto, mesmo antes dessas duas referências, tem-se a influência da escola de Frankfurt, que, desde meados de 1924, atuou na produção da filosofia mundial. Na segunda guerra mundial, esta escola teve de se transportar da Alemanha para Genebra, Paris e depois Columbia/EUA, onde ficou até 1948, e, posteriormente, retornou à Alemanha, deixando, porém, um de seus integrantes, que inspirou naquele país os movimentos pacifistas e estudantis com seu auge no chamado "maio de 1968"7, movimento ecoado em todo mundo (ALVES; ALVARO, 2006).

No campo CTS, a escola de Frankfurt contribuiu com a chamada Teoria Crítica e um de seus expoentes, Horkheimeir, fazia uma análise que vinculava a ciência a outras dimensões da vida social, entre elas a economia. Horkheimer (2003, p. 17) afirma o seguinte:

\footnotetext{
${ }^{7}$ Refere-se aos protestos de maio de 1968 realizados por movimentos estudantis, em face da insatisfação com o sistema educacional francês.
} 
[...] a realidade social, o desenvolvimento dos homens que atuam historicamente, contém uma estrutura que cuja compreensão exige a imagem teórica dos processos radicalmente transformadores, que subvertem todas as relações culturais e que de nem um modo podem ser apreendidos com os procedimentos da velha ciência natural, ajustados ao registro do que se repete.

A visão da teoria crítica, portanto, tem grande peso na discussão com enfoque em CTS, pois a análise que pretende é desvinculada daquela imposta pelas ciências naturais que Horkheimeir denomina de "velha ciência natural", chamando atenção que a mera repetição de fatos não pode explicar os processos transformadores da sociedade, o que será levado adiante pela abordagem CTS, mas com outros autores.

Desse cenário, começa a surgir o movimento CTS, propondo a superação do modelo de decisões tecnocráticas relativas à sociedade, que envolvem ciência e tecnologia (DAGNINO, 2008); não se trata de derrubar quem está no poder e, sim, influenciar em suas decisões e, para tanto, deve-se demover a ideia de ciência "neutra" e tecnologia "pura", para que se possa contestar decisões tecnocráticas sem a desculpa de que estas não são influenciáveis, pois baseadas em decisões de uma parte da sociedade.

Portanto, analisar "[...] a construção social da tecnologia é fundamental para a democratização das relações sociais de produção e da própria sociedade" (DAGNINO, 2008, p. 213). Esses autores problematizam sobre o real motivador da tecnologia, que, em vez do lucro, deveria ser a sociedade. Dagnino (2008) chama a situação citada anteriormente de "contratação da tecnologia", que consiste em uma ciência e tecnologia apropriadas para atender a sociedade.

Ziman (1980), criador do termo CTS (do inglês, STS, ScienceTechnology-Society), informa que, em meados de 1950-1960, a ideia principal sobre o ensino de ciências era priorizar somente o conteúdo válido, estabelecido nos currículos, ratificado pela ciência; pois a intenção era de se criar jovens cientistas, ignorando-se, portanto, tanto 
as questões sociais como os que não seriam cientistas. Em resumo, ignorava-se toda sociedade, ao suprimir de suas formações um caráter mais crítico ao abordar o ensino de ciências.

O autor supracitado ressalta que o objetivo da educação CTS não é o de substituir a educação formal, mas torná-la um processo consciente. Santos (2010) anuncia um dos principais objetivos do ensino CTS, qual seja, a formação de cidadania por meio do desenvolvimento da capacidade de "tomada de decisão". Esta relaciona-se à "[...] solução de problemas da vida real que envolvem aspectos sociais, tecnológicos, econômicos e políticos, o que significa preparar o indivíduo para participar ativamente na sociedade democrática" (SANTOS, 2010, p. 75).

Enquanto isso, no Brasil, Paulo Freire (2003) afirmava que alfabetizar é mais do que ler palavras e que deve proporcionar uma "leitura do mundo", visto que nos encontramos em uma "cultura do silêncio", nos alijando do processo histórico; quando a prática docente se detém somente na parte técnica do ensinar, corre-se o risco de fazer parte desta "cultura do silêncio", por não provocar uma educação que busque reflexões além do conteúdo, reforçando-se, assim, a ideia de que a ciência não carece de retoque e suas decisões não têm reflexo na sociedade, uma vez que são embasadas em pressupostos técnicos que não podem ser contestados, porquanto, nesta perspectiva, a ciência, supostamente, é pura, neutra e verdadeira.

Krasilchik (1987), ao tratar dos objetivos gerais do livro de ciências, aponta como um desses objetivos: "Analisar as implicações sociais do desenvolvimento científico e tecnológico, a natureza e importância da tecnologia, seus alcances e limitações" (KRASILCHIK, 1987, p. 67). Embora a autora não cite o termo CTS, fica claro que está tratando dele, pois no objetivo citado encontram-se os elementos do enfoque CTS, quando ela sugere a análise das implicações sociais da ciência e da tecnologia. 
No Brasil, verifica-se o surgimento de trabalhos referentes ao ensino de ciências, via CTS, em Santos e Schneltzer (2010), bem como em Auler e Delizoicov (2006), ao tratarem sobre concepções de professores de ciências relativas às interações CTS, discutindo as principais tendências nas concepções destes professores e as dimensões a serem consideradas no processo formativo.

O enfoque CTS, no ensino de ciências, encontra-se, inicialmente, nos estudos sobre alfabetização científica e tecnológica (CACHAPUZ et al., 2008; ARAUJO, 2009), a partir dos quais são produzidos artigos sobre o estado da arte em CTS e evidenciando o crescimento das pesquisas nesta área até 2006. Como nas duas pesquisas anteriormente citadas, o enfoque CTS tem despertado interesse no campo das pesquisas em Educação em Ciências, por se tratar de uma abordagem voltada para a cidadania.

É justamente essa diversidade de olhares que propicia vários modos de tratar a referida abordagem, dependendo da forma como o pesquisador instrumentaliza sua análise. O primordial, porém, é que todos têm como ponto de partida a certeza de que ciência e tecnologia não estão dissociadas das construções sociais, que servem ora para justificar ora para refutar os parâmetros que a ciência estabelece como "verdade científica" (BOURDIEU, 1976).

Assim, infere-se que o enfoque em CTS se propõe não somente a produção de novos conhecimentos, mas também se preocupa com os desdobramentos destes últimos e sua apropriação social, diferenciando esta tendência das demais, ao mesmo tempo em que torna-a propícia àqueles que desejam investigar as interações entre ciência, tecnologia e sociedade.

\section{ASPECTOS METODOLÓGICOS}

A pesquisa ora apresentada enquadra-se na abordagem qualitativa, precisamente no contexto de uma pesquisa-ação. Thilollent 
(2008, p. 16) entende a pesquisa-ação como (...) um tipo de pesquisa social com base empírica, que é concebida e realizada em estreita associação com uma ação ou com a solução de um problema coletivo, no qual os pesquisadores e os participantes representativos da situação ou problema estão envolvidos de modo participativo ou cooperativo.

Para Gil (2002), trata-se de um tipo de pesquisa que prioriza a interação entre o pesquisador e os sujeitos-colaboradores da investigação. Elegemos a pesquisa-ação por compreender também que ela

[...] não é constituída apenas pela ação ou pela participação. Com ela é necessário produzir conhecimento, adquinir experiência, contribuir para a discussão ou fazer avançar o debate acerca das questões abordadas (THIOLLENT, 2008, p. 24).

Então, podemos referir que não se trata de uma mera intervenção, mas sim de uma experiência permeada por reflexões e análises sobre a ação.

A pesquisa se deu no âmbito de um curso de extensão, intitulado "Energia e sustentabilidade: um desafio contemporâneo", envolvendo alunos de diferentes licenciaturas, precisamente na atividade denominada "música no varal", cujo objetivo era problematizar os impactos da exploração e da ocupação da Amazônia, retratados na música "Saga da Amazônia", de Vital Farias (FARIAS, 1984)8. A atividade consistiu no fornecimento de diferentes estrofes da música para cada aluno participante do curso, de modo que eles pudessem analisar criticamente o seu conteúdo.

Participaram como sujeitos da pesquisa três alunos de química, dois alunos de biologia, um de física, um de ciências naturais e, por fim, um de geologia. Os participantes foram identificados de "Participante 1" a "Participante 10". Com a análise da música pelos alunos, buscamos

${ }^{8}$ Disponível em: <https://www.letras.mus.br/vital-farias/380162/>. Acesso em: 8 mar. 2020. 
apreender a percepção destes quanto à identificação dos atores sociais tradicionais da Amazônia, dos discursos políticos sobre a Amazônia, da mudança na vida tradicional da população da Amazônia paraense, bem com a problematização destes aspectos frente à utilização dos recursos naturais e às questões de (in)sustentabilidade.

\section{APREENSÕES SOBRE A AMAZÔNIA}

De um modo geral, os alunos se posicionaram criticamente em relação ao contexto apresentado na música "Saga da Amazônia". Vejamos então os comentários dos alunos a respeito das estrofes:

Mas o dragão continua a floresta devorar E quem habita essa mata pra onde vai se mudar??? Corre o índio, seringueiro, preguiça, tamanduá Tartaruga, pé ligeiro, corre-corre tribo dos kamaiurá" (FARIAS, 1984, $2^{a}$ estrofe).

Participante 4: terceiro verso relatando o que destrói a madeira: fato que serve as máquinas usadas para extração de madeira que maioria das vezes de formas absurdas, gerando o problema de desmatamento (P4).

O Participante 4 consegue relacionar a estrofe com a forma predatória da exploração da madeira. De fato, a Amazônia, ao longo dos tempos, tem sofrido depleção severa dos seus recursos madeireiros (FILHA GARRIDO, 2002). Certamente o pressuposto da sustentabilidade foi comprometido pela voracidade da atividade econômica que explora a madeira na Amazônia. Entendemos, como Ramos (2004), que alunos ao identificarem problemas locais, podem, no processo de ensino e de aprendizagem, relacionar as questões teóricas e práticas com sua realidade.

Fizeram logo o projeto sem ninguém testemunhar. Pro dragão cortar a madeira e toda a mata derrubar. Se a floresta meu amigo tivesse pé prá andar eu garanto meu amigo, com o perigo não tinha ficado lá (FARIAS, 1984, $2^{a}$ estrofe); 
Participante 8: Esta questão do projeto é muito difundida em determinadas aulas de biologia, em disciplinas de legislação ambiental. Casos como o dos biólogos presos e mantidos reféns por índios que os flagraram estudando a área da aldeia sem permissão prevista por lei, no ano passado, são mais comuns do que se imagina. Esta documentação é obrigatória, por requerer trabalho de biólogos, ambientalistas de toda uma equipe muito preparada, e muitas vezes ignorada ou subestimada pelas empresas que acabaram fazendo de qualquer jeito (P8)

Nesse comentário, feito por outro participante, Participante 8, novamente é possível perceber relações do que a música retrata com uma situação local, ou seja, ignorou-se a lei vigente em função do lucro e da velocidade que a produção exige. Esse tipo de relação é muito importante quando se trabalha o ensino de ciências via o enfoque CTS, - qual pretende fomentar uma visão mais crítica a respeito das situações que nos rodeiam (SANTOS; SCHNETZLER, 2010).

Toda mata tem caipora para mata vigiar. Veio caipora de fora para a mata definhar. E trouxe dragão de ferro pra comer muita madeira. E trouxe estilo gigante pra acabar com a capoeira (FARIAS, 1984, $7^{\mathrm{a}}$ estrofe).

Participante 7: Ainda fazendo um paralelo em que a música em questão e o tema, modelo de desenvolvimento, podemos notar claramente pontos deste processo simbolizados na letra da música, como o caipora, que representa o líder de algum grupo. O caipora da mata seria o líder de alguma tribo indígena, enquanto o caipora de fora, seria um líder de outra civilização, no caso capitalistas ocidentais. O dragão de ferro estaria simbolizando as ferramentas utilizadas para a retirada da vegetação, e o estilo gigante seria consequência da implantação desse novo sistema de relações sócio ambientais o que é antagoniza no sistema natural das sociedades nativas (P7).

No comentário acima, o Participante 7 busca relações da estrofe da música com o modelo de desenvolvimento adotado. Faz relação também com a implantação de projetos sem levar em consideração a comunidade local e, portanto, negligenciando os interesses e as necessidades dessas comunidades. Ao observar o cenário atual da região, percebe-se que o comentário acima mostra-se atual e está plenamente de acordo com a forma como os projetos são propostos na região (LOUREIRO, 2002; TRECCANI, 2001). 
No Lugar que havia mata hoje a perseguição. Grileiro mata posseiro só pra lhe roubar seu chão. Castanheiro, seringueiro já viram até peão. Afora os que já morreram qual ave-de-arribação. Zé de nana tá de prova naquele lugar tem cova. Gente enterrada no chão (FARIAS, 1984, 4a estrofe)

Participante 9: Aqui na nossa cidade de Belém, existem muitos lugares que são invadidos, sendo que a maioria dessas pessoas já possuem uma casa para morar, mesmo assim acabam invadindo, e acaba tendo conflito com o proprietário da terra invadida. Portanto, esses conflitos acabam tendo as rebeliões, por essa briga de terra, entre proprietário e os sem terras, as autoridades acabam sendo acionadas por causa da invasão, como os sem terra não acabam cedendo, acaba tendo as mortes de homens, mulheres e crianças. Como diz a música (naquele lugar tem cova gente enterrada no chão) (P9).

O Participante 9 conseguiu perceber a relação entre os conflitos de terra no campo com os conflitos e invasões de propriedades na cidade em que reside, relacionando ainda a interferência do poder público com a questão problema levantada pela música. Em verdade, muitos projetos no estado do Pará e na Amazônia sofrem a interferência do poder público, que acaba por garantir e salvaguardar os interesses das grandes empresas, servindo a estas, enquanto deveria servir também à população atingida por esses projetos (PINTO, 2012).

O que se corta em segundos gasta tempo prá vingar E o fruto que dá no cacho pra gente se alimentar?? Depois tem o passarinho, tem o ninho, tem o ar lgarapé, rio abaixo, tem riacho e esse rio que é um mar. (FARIAS, 1984, $3^{a}$ estrofe).

Participante 5: Há algum tempo percebi o desaparecimento de uma certa fruta que eu gosto muito, maçã. A banana se reproduz como clone e essa em especial desaparecer para o maior consumo por um certo tempo, mais ou menos uns 2 anos. A colheita sem critérios pode acarretar na extinção de um determinado fruto, assim como a perda em período de reprodução, pode se colocar em risco a espécie. Devemos atentar que todo ser vivo precisa de um tempo para germinar, crescer o que então ficar apto para o que é proposto ou até imposto a ele (P5).

A Participante 5 consegue relacionar a utilização de um recurso natural, enxerto em uma planta, para produzir uma espécie de banana que é mais doce, chamada de banana maçã, com a sua exploração, 
e relata que por um excesso na coleta da mesma, percebeu seu exaurimento e a escassez durante dois anos. A referida aluna trabalha em feiras livres, atividade que the permitiu perceber esse fato e relacionar a música com a situação problema de seu cotidiano, além de refletir sobre a utilização de recursos naturais e também sobre a possiblidade da velocidade de produção levar à extinção de uma espécie, conforme é destacado por Barbiere (2012).

De um modo geral, a atividade "música no varal" possibilitou discussões sobre sustentabilidade, em uma perspectiva multidimensional. Além do mais, observou-se a relação teoria-cotidianoação, nos termos de Thiollent (2008).

\section{CONSIDERAÇÕES FINAIS}

A atividade "Música no Varal", alcançou seus objetivos, visto que os alunos problematizaram algumas das questões relacionadas à Amazônia, notadamente aquelas que dizem respeito à interferência no meio ambiente em comunidades tradicionais da região. Também percebemos que um dos objetivos relativos ao enfoque CTS foi alcançado, uma vez que emergiram visões mais críticas das relações CTS.

A música "Saga da Amazônia" constituiu-se oportunidade para o estabelecimento de relações interdisciplinares na abordagem da temática proposta. Como veículo de expressão, "Saga da Amazônia" aproximou o discente do tema tratado, de forma prazerosa. É nesse contexto que a música, parte do nosso cotidiano, é particularmente "útil" ao fazer docente que se propõe renovar e dinamizar o ensino.

\section{REFERÊNCIAS}

ALVES, D. M.; ALVARO, A. L. T. Herbert Marcuse e a teoria crítica. Revista Científica Eletrônica de Psicologia, Garça, n. 6, p. 1-10, 2006. 
ANGOTTI, J. A. P.; AUTH, M. A. Ciência e tecnologia: implicações sociais e o papel da educação. Ciência \& Educação, Bauru, v. 7, n. 1, p. 15-27, 2001.

ARAUJO, R. F. Os grupos de pesquisa em ciência, tecnologia e sociedade no Brasil. Revista Brasileira de Ciência, Tecnologia e Sociedade, São Carlos, v. 1, n. 1, p. 81-97, 2009.

AULER, D.; BAZZO, W. A. I. Reflexões para a implementação do movimento CTS no contexto educacional brasileiro. Ciência \& Educação, Bauru, v. 7, n. 1, p. 1-13, 2001.

AULER, D.; DELIZOICOV, D. Ciência-Tecnologia-Sociedade: relações estabelecidas por professores de ciências. REEC: Revista electrónica de enseñanza de las ciencias, v. 5, n. 2, p. 337-355, 2006.

BARBIERI, E. Biodiversidade: a variedade de vida no planeta Terra. Centro Avançado de Pesquisa Tecnológica do Agronegócio do Pescado Marinho, Instituto de Pesca, São Paulo, abril de 2010.

BECKER, B. K. Amazônia: geopolítica na virada do III milênio. Rio de Janeiro: Garamond, 2009.

BOURDIEU, P. Le champ scientifique. Actes de la Recherche en Sciences Sociales, Paris, n. 2/3, p. 88-104, 1976.

CACHAPUZ, A. et al. Do estado da arte da pesquisa em educação em Ciências: linhas de pesquisa e o caso "Ciência-Tecnologia-Sociedade. ALEXANDRIA. Revista de Educação em Ciência e Tecnologia, Florianópolis, Santa Catarina, v. 1, n.1, p. 27-49, 2008.

CARSON, R. Primavera Silenciosa. São Paulo: Gaia, 2010.

DAGNINO, R. Neutralidade da ciência e determinismo tecnológico: um debate sobre a tecnociência. Campinas, SP: Editora da UNICAMP, 2008.

DEMO, P. Educar pela pesquisa. Campinas, SP: Editora Autores Associados, 1998.

DIAS, R. D. O. Deslocamento na formação de professores: aprendizagem de adultos, experiência e políticas cognitivas. Rio de Janeiro: Lamparina, 2011. 
ELLIOTT, J. La investigación-acción en educación. Ediciones Morata, S. L, 1990.

FARIAS, V. Saga da Amazônia. Salvador: CD Cantoria 1, 1984.

FAZENDA, I. C. A. Didática e Interdisciplinaridade. Local: PAPIRUS, 2008.

FREIRE, P. Pedagogia do oprimido. Rio de Janeiro: Edições Paz e Terra, 2003.

GARRIDO FILHA, I. Manejo florestal: questões econômico-financeiras e ambientais. Estudos Avançados, São Paulo, v.16, n.45, p. 91-106, 2002.

GERALDI, C. M. G.; FIORENTINI, D.; PEREIRA, E. M. A. Cartografia do trabalho docente: professor(a)-pesquisador(a). Campinas: Mercado de Letras, 1998.

GIL, A. C. Como elaborar projetos de pesquisa. 4 ed. São Paulo: Atlas, 2002.

GONÇALVES, C. W. P. Amazônia e Amazônias. São Paulo: Contexto, 2019.

HORKHEIMER, M. Teoria crítica. Buenos Aires: Amorrortu, 2003.

KRASILCHIK, M. O professor e o currículo das ciências. São Paulo: Editora Pedagógica e Universitária, 1987.

KUNH, T. S. O caminho desde a estrutura. São Paulo: Unesp, 2006.

LOUREIRO, V. R. Amazônia: história e análise de problemas: do período da borracha aos dias atuais. 2a . ed. Belém: DISTRIBEL, 2002.

LUJÁN LÓPES, J. L. et al. Ciencia, Tecnología y Sociedad: una introducción al estudio social de la ciencia y la tecnología. Madrid: TECNOS, 1996

MELLO, N. A. Políticas territoriais na Amazônia. Petrópolis, RJ: Vozes, 2006.

PINTO, L. F. Hidrelétricas na Amazônia: predestinação, fatalidade ou engodo? Belém: Edição Jornal Pessoal, 2002. 
PINTO, L. F. A Amazônia em questão: Belo Monte, Vale e outros temas. São Paulo: B4 Editores, 2012.

RAMOS, M. G. Educar pela Pesquisa é Educar para a argumentação. In: MORAES, R.; LIMA, V. M. D. R. Pesquisa em sala de aula: tendências para educação em novos tempos. 2. ed. Porto Alegre: EDIPUCRS, 2004.

SANTOS, W. L. P. D.; SCHNETZLER, R. P. Educação em química: compromisso com a cidadania. ljuí: Unijuí, 2010.

THIOLLENT, M. Metodologia da pesquisa-ação. São Paulo: Cortez, 2008.

TRECCANI, G. D. Violência e grilagem: instrumentos de aquisição da propriedade da terra no Pará. Belém: UFPA: ITERPA, 2001.

TRIVELATO, S. L. F. O ensino de ciências e as preocupações com as relações em CTS. Educação em Foco, Juiz de Fora, v. 5, n. 1, p. 43-54, 2000.

ZIMAN, J. M. Teaching and Learning about Science and Society. Cambridge University Press, 1980. 


\title{
O LÚDICO NA APREENSÃO DAS QUESTÕES CTS?
}

\author{
Josyane Barros de Abreu \\ Darlene Teixeira Ferreira \\ Nívia Magalhães da Silva Freitas \\ Chirla Miranda da Costa \\ Elinete Oliveira Raposo \\ Nadia Magalhães da Silva Freitas \\ "[...] Mas oh, não se esqueçam da rosa \\ de Hiroshima / A rosa hereditária / A \\ rosa radioativa / Estúpida e inválida / A \\ rosa com cirrose / A anti-rosa atômica/ \\ Sem cor sem perfume / Sem rosa sem \\ nada." \\ Gerson Conrad e Vinícius de Moraes.
}

\section{INTRODUÇÃO}

A humanidade vive sob o auspício e o domínio da ciência e da tecnologia, cuja crença em relação a estas é tão intensa que chega a ser semelhante a uma adoração divina (BAZZO, 2010). Essa fé na relação Ciência e Tecnologia (C\&T) tem um contexto histórico marcado por crises e conflitos, a exemplo de eventos como a segunda Guerra Mundial e a Guerra Fria que, certamente, foram guerras tecnológicas, tendo como vitoriosos aqueles com a "melhor ciência".

Dentre os acontecimentos marcantes da segunda metade do século XX, a corrida armamentista evidencia grande avanço da C\&T com o lançamento do Sputnik10. A conquista do espaço representou o ápice do avanço científico e tecnológico, o que motivou grandes

\footnotetext{
9 Publicado originalmente no Congreso Iberoamericano de Ciencia, Tecnología, Innovación y Educación, em 2014, revisado e atualizado.

10 Sputinik, o primeiro satélite artificial a orbitar a Terra. Seu lançamento, em 04 de outubro de 1957, tinha como objetivo determinar a densidade das camadas mais altas da atmosfera, tendo seus dados transmitidos por meio de sinais de rádio (BIP-BIP-BIP) que podiam ser escutados por radioamadores em qualquer lugar do mundo. Sua atividade funcional durou 21 dias. Disponível em:
} http://www.karl.benz.nom.br/hce/satelite/sputnik/sputnik.asp. Acesso em: 08 set 2014. 
investimentos para pesquisas científicas, mostrando a ciência como um campo fértil para o progresso da humanidade. O crescimento da área foi tão grande que o posto de cientista representava uma posição de prestígio e era almejada por muitos na hora da escolha profissional (KRASILCHICK, 1987).

Mas o que essa corrida espacial tem a ver com a ciência que nos é ensinada hoje? Chassot (2004) nos fala sobre os reflexos do período pós-guerra nos currículos de ciências no Brasil e nos mostra o quanto a visão de ciência benfazeja e ingênua tem nos constituído como cidadãos inábeis para pensar as questões que envolvem ciência e tecnologia. O evento Sputnik não marcou apenas os modelos curriculares dos Estados Unidos, mas reverberou também nas salas de aula brasileiras.

Na década de 1970, o maior objetivo do ensino de ciências era formar pequenos cientistas e, para isto, o sistema educacional do país mobilizou inúmeros esforços para alcançá-lo, e teve como caminho promissor para esse "encantamento" da ciência o treinamento de professores (CHASSOT, 2004). Com a popularização do conhecimento científico, a imagem de ciência e de tecnologia propagada em nossas salas de aula foi, como Bazzo (2010) diz, a de amigas leais, que arrastam consigo apenas benesses para a sociedade.

É certo que, por muito tempo, a percepção das relações C\&T balizava-se no pensamento de que a combinação de ambas só ocasionaria benefícios para a sociedade. Segundo Lima Júnior et al. (2014, p. 176), "[...] ainda hoje é uma visão que pode estar sendo incentivada pelos próprios professores das áreas de Ciências Naturais". Entretanto, são inúmeros os eventos contemporâneos que nos mostram que a relação Ciência, Tecnologia e Sociedade (CTS), por muitas vezes, tem sido desarmônica.

Eventos como o bombardeamento das cidades de Hiroshima e Nagasaki, a publicação das obras de Thomas Kuhn, "A estrutura das revoluções científicas", e da bióloga naturalista Rachel Carson, Sumário - 
"Primavera silenciosa", somados a eventos mais atuais de contaminação do solo, acidentes nucleares, destruição da camada de ozônio etc., fizeram e têm feito com que a população estendesse olhares para uma visão mais crítica para os produtos da relação C\&T.

É nesse cenário de desconfiança dos reais objetivos da C\&T que nasce o movimento CTS. Para Pinheiro (2005), corresponde ao estudo das interlocuções entre ciência, tecnologia e sociedade, buscando entender os aspectos sociais do desenvolvimento técnico e científico, tanto em relação aos benefícios que este desenvolvimento possa trazer como também às consequências sociais e ambientais que poderá causar.

Apesar do movimento não ter sua origem no ambiente educacional, as reflexões nessa área têm crescido significativamente, por entender que a escola é um espaço próprio para que as mudanças comecem a acontecer (PINHEIRO, 2005). Vaz, Fagundes e Pinheiro (2009) atentam para o fato de os professores de ciências não compreenderem as interações CTS, O que pode dificultar a emancipação do enfoque CTS na formação de cidadãos conscientes, precisamente dos benefícios e dos malefícios imbricados na relação C\&T. Santos e Schnetzler (2010) apontam como problemas e desafios para a implementação do ensino com enfoque CTS a não inclusão do tema nos exames de seleção, a escassez de material didático pedagógico e a necessidade de redefinição de conteúdos.

A educação científica passou por um período de cegueira em relação às consequências que o uso do conhecimento científico poderia ocasionar à sociedade, em virtude do obscurantismo técnico (VASCONCELOS; FREITAS, 2012) e da fulgência dos benefícios produzidos. Educar numa perspectiva CTS é fundamentalmente possibilitar uma formação para maior inserção social das pessoas, no sentido de ser tornarem aptas a participarem dos processos de tomada de decisões conscientes e negociadas em assuntos que envolvam a ciência e a tecnologia (CASSIANI; LISINGEN, 2009). 
Cachapuz (2012, p.14) nos faz pensar sobre a necessidade de desenvolver uma "[...] cultura científica que nos permita participar de decisões racionais, compreender minimamente os processos de decisões mais complexos e o sentido de desenvolvimento tecnocientífico". Para isso, faz-se necessário que nossas salas de aula propiciem campo fértil para o surgimento dessa nova cultura.

O fato é que a "[...] ciência conquistou o poder de não só modelar as nossas vidas, mas também de modificar a vida" (CACHAPUZ, 2011, p. 50), o que exige de nós um olhar mais crítico para as facetas que envolvem o progresso científico. As relações entre tecnociência e poder devem ser reformuladas de forma mais democrática e humanista (CACHAPUZ, 2011).

Nesse sentido, cabe ao professor deslocar o aluno do lugar de mero telespectador dos fatos para a cena de cidadão ativo - aquele que pode refletir e propor soluções (AMARAL, 2005). Para tal, acreditamos que fazendo uso do lúdico, juntamente com atividades centradas nos alunos, em qualquer nível de ensino, podemos tornar o espaço de sala de aula mais atrativo e motivador para o trabalho de temas que envolvam as relações CTS, na aproximação dos estudantes com o conhecimento científico. Como instrumento pedagógico, o lúdico é considerado um poderoso recurso para favorecer o registro de um determinado tema na memória dos estudantes ou levá-los, por meio de um impacto emocional, a refletir sobre determinada questão (SOUSA et al., 2012).

Há várias atividades consideradas lúdicas que podem ser incorporadas na sala de aula para discutir as mais variadas questões; entre elas, podemos destacar o jogral, o teatro, jogos, paródias, pinturas e músicas. Neste trabalho, adotamos a música como recurso lúdico para discutir questões pertinentes à relação CTS. De acordo com Barros, Zanella e Araújo-Jorge (2013), na antiguidade a música ocupava lugar de destaque e era disciplina obrigatória nos currículos básicos. No entanto, segundo Granja (2006), ao longo do tempo, a música foi 
perdendo espaço e o conhecimento técnico científico passou a sobrepor os conhecimentos de natureza artística.

Algumas vantagens na introdução da música, como recurso didático pedagógico, durante as aulas de Ciências são consideradas (BARROS; ZANELLA; ARAÚJO-JORGE, 2013), a saber: (a) é uma alternativa de baixo custo; (b) é uma oportunidade para estabelecer relações interdisciplinares; (c) é uma atividade lúdica que ultrapassa a educação formal e (d) é uma atividade cultural. Nesse sentido, fazendo uso da letra da canção "Rosa de Hiroshima", poetizada por Gerson Conrad e Vinícius de Moraes, cantada por Ney Mato Grosso, objetivamos problematizar os aspectos implicados na relação CTS, precisamente no contexto da formação inicial de professores de Ciências.

\section{METODOLOGIA}

A pesquisa enquadrou-se na modalidade qualitativa. Destacamos que a pesquisa qualitativa trabalha com um universo de percepções, significados, crenças, valores e atitudes (DELANDES, 2016). Nesse contexto, o trabalho configura-se como de pesquisa-ação, nos termos de Barbier (2007, p. 53), o qual observa o seguinte:

Se por muito tempo o papel da ciência foi descrever, explicar e prever os fenômenos, impondo ao pesquisador ser um observador neutro e objetivo, a pesquisa-ação adota um encaminhamento oposto pela sua finalidade: servir de instrumento de mudança social [...] a pesquisa ação postula que não se pode dissociar a produção de conhecimentos dos esforços feitos para levar à mudança.

Cabe lembrar, que a ação não se trata de uma mera intervenção, para a mera recolha de dados. Trata-se, no entanto, de uma experimentação social, não no sentido da experimentação 
científica, mas sim, da experiência vivida, permeada por reflexões e análises empreendidas sobre a ação.

A ação aconteceu no contexto de desenvolvimento de uma abordagem de ensino temático, pautada nos pressupostos epistemológicos do enfoque CTS, intitulada "Usos e abusos da energia nuclear", e contou com a participação dos licenciados do Curso de Licenciatura em Ciências, Matemática e Linguagens, da Universidade Federal do Pará. Pretendeu-se promover uma vivência de uma abordagem CTS, envolvendo uma sequência de ensino que, segundo Vieira, Reginatto e Chieff (2009, p.13), é:

[...] planejada, organizada passo a passo e orientada pelo objetivo de promover uma aprendizagem definida. São atividades sequenciadas, com a intenção de oferecer desafios de diferentes complexidades para que os alunos possam, gradativamente, apropriarem-se de conhecimentos, atitudes e valores considerados fundamentais.

Esse conjunto de sequências foi acompanhado de questões norteadoras e atividades, as quais demandaram pesquisa bibliográfica, leitura e análise de textos, filme e música, discussões dirigidas, produção de textos, debates ante uma controvérsia sociocientífica, exposição, etc. No entanto, para fins deste texto, trouxemos um recorte de análise, precisamente a análise crítica da canção "Rosa de Hiroshima", poetizada por Vinícius de Moraes e cantada por Ney Mato Grosso. No momento da situação de estudo, os alunos foram convidados a ouvir a canção e refletir criticamente sobre o seu conteúdo.

Os dados coletados foram organizados e analisados mediante análise textual discursiva. Segundo Moraes e Galiazzi (201 1, p. 7), "[...] corresponde a uma metodologia de análise de dados e informações de natureza qualitativa com a finalidade de produzir novas compreensões sobre os fenômenos e discursos". A análise textual "[...] trabalha com textos, podendo partir de materiais já existentes ou esses 
podem ser produzidos dentro da própria pesquisa" (MORAES, 2007, p. 87).

Cabe destacar que o "[...] conjunto de textos submetidos à análise costuma ser denominado de corpus [corresponde a uma] multiplicidade de vozes se manifestando sobre os fenômenos investigados" (MORAES, 2007, p. 87). É do corpus que são retirados os elementos utilizados na elaboração de um novo texto, o metatexto, cuja função é apresentar os resultados das análises (FERREIRA, 2011).

De acordo com Moraes (2007, p. 100), um metatexto, para ser adequado, deverá ser construído "[...] a partir da inserção no texto de falas e citações de fragmentos dos textos analisados", denominadas de interlocuções empíricas. Na interpretação dos metatextos, as interlocuções teóricas, ou seja, diálogos com autores que discutem os temas, os fenômenos, os processos etc., são também relevantes para a validação.

Complementarmente, adotamos ainda a metodologia de análise utilizada em pesquisas de Etnociências, para a construção da "Matriz de Cognição Comparada", como as de Barbosa (2006), Caló (2007), Marques (2001), Martins (2008) e Rodrigues (2008). No âmbito do nosso trabalho, trechos das respostas e considerações dos discentes (interlocuções empíricas - identificadas com a palavra Aluno e número correspondente) foram comparados com citações constantes na literatura pertinente à área (interlocuções teóricas - Apoio). Em ambos os casos, os trechos foram destacados em negrito na apresentação dos resultados.

\section{SUPERANDO UMA VISÃO INGÊNUA DA RELAÇÃO C\&T}

Vários aspectos implicados nas relações CTS foram indicados nas leituras da canção pelos alunos. Trazemos aqui as questões de maior recorrência nas assertivas dos alunos, quais sejam: poder, meio 
ambiente e saúde humana. A seguir veremos cada uma delas de formar mais detalhada.

\section{Poder}

Emerge na fala de alguns alunos, como pode ser visto abaixo, o peso de culpa do homem, ao fazer uso da tecnologia - a bomba - em eventos catastróficos, somente para demonstrar poder e conquista sobre o outro:

Aluno 2: "[...] que não esqueçam da rosa que ficará no tempo e que ficou na história como uma lembrança negativa e egoísta pela busca do poder";

Aluno 28: "Este [evento] que vitimou milhares de pessoas, sem que houvesse alguma necessidade para que isso ocorresse, apenas foi usado como forma de mostrar o poder bélico, o poder nuclear, a força do exército americano";

Aluno 35: "O poema "Rosa de Hiroshima" revela um olhar crítico à ambição de poder e a falta de conscientização dos homens.".

Aluno 37: "Vinício de Moraes [...] convida-nos a pensar nas crianças, mulheres e todas que ficaram mudas, telepáticas, cegos e extremamente marcados pela violência e maldade de homens em busca de demonstração de conquista e poder sobre outros".

Apoio: a "[...] história é muito diferente quando a ciência está a serviço do governo ou de uma entidade internacional, patrocinada por vários governos [...] a ciência é sem dúvida uma ferramenta de governo, mas ao mesmo tempo o governo e seu poder são de algum modo forçados a ficar ao seu senviço. Entre a ciência e o poder, desenvolve-se uma curiosa relação senhor-escravo" (FERRAROTI, 1998, p. 59).

O Aluno 28, na sua assertiva, relaciona o poder do governo americano às tragédias ocorridas com a explosão da bomba atômica, destacando como a ciência em mãos inconsequentes pode perder sua real essência. A ciência em sua natureza, na antiguidade clássica, se apresentava à margem da sociedade, com pouco prestígio e valor, porém a situação muda com as guerras e conquistas territoriais. 
Com associação da ciência ao Estado e à política, os cientistas passam a dispor suas descobertas a serviço do poder; a ciência precisa cada vez mais do apoio do governo e uma relação recíproca se estabelece. Tais aspectos são corroborados por alguns autores, a saber:

\begin{abstract}
Apoio: Angotti e Auth (2001), com 0 arsenal de guerra, principalmente com a construção de bombas atômicas, ficou evidente o poder destrutivo do homem na relação C\&T. Como declara Japiassu (2011, p.18-19), o "[...] objetivo da nova ciência [...] consiste em dominar a natureza, isto é, tornar-nos seus 'mestres e possuidores', porque o Saber e o Poder andam juntos".
\end{abstract}

As questões apontadas pelos sujeitos nos mostram o quanto a ciência e suas aplicações podem se tornar armas que impactam profundamente a sociedade, dependendo de quem a tem sob o controle. O lançamento da bomba atômica em Hiroshima e Nagasaki contribuiu para ratificar que os resultados e as aplicações da ciência e da tecnologia podem associar-se à externalidades negativas (ANGOTTI; AUTH, 2001). Para nos referir à questão do poder, trazemos as observações de Morin (2005, p. 18), quais sejam:

Os poderes criados pela atividade científica escapam totalmente aos próprios cientistas [...] os cientistas produzem um poder sobre o qual não têm poder, mas que enfatiza instâncias já todo-poderosas [...] de manipulação e de destruição provenientes do próprio desenvolvimento da ciência.

Assim, percebemos que a conquista mediada pelo poder da relação ciência e tecnologia aparece como fator de devastação e destruição, remetendo a consequências negativas de cunho humano e social.

Em realidade, a humanidade faz uso da ciência para dominar a natureza e ao próprio homem, porque o saber e o poder andam juntos. Mas também reconhecemos que "[...] o poder significa energia para fazer" (JARA, 1998, p. 75) e, neste sentido, novas formas de poder 
emergem, a saber: poder da solidariedade, poder da consciência e poder do diálogo, entre outros; e são essas formas de poder que devemos emancipar nas relações C\&T, pois, assim, certamente, tais poderes constituiriam sociedades mais humanas e justas.

\section{Meio ambiente}

Os eventos que conformam a crise ambiental atual têm relação intrínseca com o entendimento de que a ciência e a tecnologia são, no conjunto, força motriz para o progresso e o desenvolvimento, entretanto, sem levar em consideração suas questões multidimensionais (BAZZO, 2010). Nesse sentido, surge também na fala dos alunos, a preocupação com os efeitos ambientais resultantes do bombardeamento das cidades japonesas, a saber:

Aluno 27: "A letra dessa canção nos faz refletir que além do desenvolvimento de enfermidades na população foi o desastre ambiental";

Aluno 28: "Sem esquecer de falar sobre os danos que essa radioatividade causou na saúde dessas pessoas que se perpetuaria de geração em geração e a destruição causada poluindo o meio ambiente";

Apoio: Efeitos radioativos, como os resultantes do bombardeamento nas cidades de Hiroshima e Nagasaki, podem ser catastróficos por causarem a devastação da biodiversidade (concentração da radioatividade nas plantas e animais), contaminação do solo, da água e do ar (COMISSÃO NACIONAL DE ENERGIA NUCLEAR, 2014).

Eventos como o ocorrido no Japão fizeram com que, pela primeira vez, reconhecêssemos a "[...] existência de um risco ambiental global: a poluição nuclear [o que nos alertou para o fato de que] estamos todos numa mesma nave, e que os problemas ambientais não estão restritos a territórios limitados" (NASCIMENTO, 2012, p. 52). Agora, o local passa a ter importância global.

Infelizmente, as questões ambientais levantadas pelos alunos não são resultantes apenas de bombardeamentos, como no evento 
histórico citado. O fato é que, avanços científicos e tecnológicos parecem caminhar à velocidade da globalização; assim, a cada piscar de olhos, novos artefatos tecnológicos surgem para substituir outros, agora já ultrapassados, e, sem pensar nas reais necessidades, fazemos uso destes produtos de forma indiscriminada. Parecemos, ainda, viver no que é chamado de sonambulismo tecnológico (WINNER, 1987 apud BAZZO, 2010), que "[...] é quando a sociedade se submete humildemente a cada nova exigência da tecnologia e utiliza sem questionar todo novo produto, seja ele positivo ou negativo para uma melhora real" (BAZZO, 2010, p. 118).

É o meio ambiente que muito tem padecido com a ambição humana, no fazer uso da tecnologia. Parece um paradoxo, mas a própria ciência tem nos apontado sinais de falência do ecossistema planetário. Diariamente somos atormentados por clichês midiáticos, informando sobre mudanças no globo, como as questões do aquecimento global, destruição da camada de ozônio, derretimento das calotas polares, queimada de florestas, contaminação de rios e etc., mas o que não atentamos é que caminhamos rumo a um agravo da crise ambiental e que pouco temos feito para minimizá-la.

Mesmo diante de uma situação de crise ambiental, que não deixa de ser social, apostamos na educação como um caminho, não como salvacionista, mas como necessária, de modo que possamos garantir a formação de cidadãos, não apenas conhecedores de conceitos científicos, mas também reconhecedores dos benefícios e dos riscos do uso desses conhecimentos para todos. É importante ressaltar que o posicionamento defendido por nós não é o de um discurso anti-ciência ou anti-tecnologia, mas tem o sentido defendido por Auler e Delizoicov (2001), no qual refletir e problematizar as relações C\&T constituem-se possibilidades de entendimento e de construção de uma imagem mais realista da atividade científica e tecnológica. 


\section{CONSIDERAÇÕES FINAIS}

É necessário incorporarmos práticas e discursos que desmitifiquem a benevolência da relação ciência e tecnologia. Do mesmo modo, não podemos deixar de reconhecer que ciência é, sim, uma área promissora para o progresso, desde que seja exercida de forma consciente e democrática. Entretanto, um requisito essencial para a renovação da educação científica é justamente a superação das visões ingênuas e deformadas da ciência e da tecnológica.

Ao desenvolverem a leitura da canção, os alunos adotaram uma postura crítica e reflexiva. E isso aponta que a participação da sociedade em questões de ciência e de tecnologia apresenta relevância, pois as mudanças na visão da ciência, avaliando seus benefícios e também seus riscos, conduzem ao abandono de uma visão neutra e ingênua da ciência. Com esses argumentos, podemos considerar a necessidade da inserção da abordagem CTS no ensino de ciências.

\section{REFERÊNCIAS}

AMARAL, M. A dimensão ambiental na cultura educacional brasileira. Revista Brasileira de Estudos Pedagógicos, Brasília, v. 88, n. 218, p. 107-12, 2007.

ANGOTTI, J. A. P.; AUTH, M. A. Ciência e Tecnologia: implicações sociais e o papel da educação. Ciência \& Educação, Bauru, v. 7, n. 1, p.15-27, 2001.

AULER, D.; DELIZOICOV, D. Alfabetização científica-tecnológica para quê? Ensaio - Pesquisa em educação em Ciências, Belo Horizonte, v. 03, n. 1, p.1-13, 2001.

BARBIER, R. A pesquisa-ação. Brasília: Livel Livro, 2007. 
BARBOSA, R. S. L. Interface conhecimento tradicional-conhecimento científico: um olhar interdisciplinar da etnobiologia na pesca artesanal em Ajuruteua, Bragança-Pará. 114 f. Dissertação (Mestrado). Programa de Pós-Graduação em Biologia Ambiental. Universidade Federal do Pará. Bragança-PA, 2006.

BARROS, M. D. M. de; ZANELLA, P. G.; ARAúJO-JORGE, T. C. A música pode ser uma estratégia para 0 ensino de Ciências Naturais? "Analisando concepções de professores da educação básica". Ensaio Pesquisa em Educação em Ciências, Belo Horizonte, v. 15, n. 1, p. 81-94, 2013.

BAZZO, W. A. Ciência, Tecnologia e Sociedade e o contexto da educação tecnológica. Florianópolis/SC: Editora UFCS, 2010.

CACHAPUZ, A. F. et al. (Org.). A necessária renovação do ensino de Ciências. São Paulo: Cortez, 2011.

CACHAPUZ, A. F. Do ensino das ciências: seis ideias que aprendi. In: CARVALHO, A. M.; CACHAPUZ, A.F.; GIL-PÉREZ, D. O ensino das ciências como compromisso científico e social. São Paulo: Editora Cortez, 2012, p.11-33.

CALÓ, C. F. F. Conhecimento ecológico local e taxonômico dos peixes "vermelhos" (Actinopterygii, Teleostei) pelos pescadores de llhéus, Bahia". 83 f. Dissertação (Mestrado). Programa de Pós-graduação em Zoologia. Universidade Estadual de Santa Cruz. Ilhéus-BA, 2007.

CASSIANI, S.; LINSINGE, I. V. Formação inicial de professores de ciências: perspectivas discursivas na educação CTS. Educar em Revista, Curitiba, n. 34, p. 127-147, 2009.

CHASSOT, A. Ensino de Ciências no começo da segunda metade do século da tecnologia. In: LOPES, A. C.; MACEDO, E. (Org.). Currículo de Ciências em debate. Campinas: Papirus, 2004. p. 13-44.

COMISSÃO NACIONAL DE ENERGIA. Princípios Básicos de segurança e proteção radiológica. Universidade Federal do Rio Grande do Sul: Comissão Nacional de Energia Nuclear, 2014.

DELANDES, S. F. A construção do projeto de pesquisa. In: MINAYO, M. C. de S. (Org.); DELANDES, S. F.; GTOMES, R. Pesquisa social: teoria, método e criatividade. Petrópolis-RJ: Vozes, 2016. p. 31-50. (Série Manuais Acadêmicos). 
FERRAROTTI, F. A revolução industrial e os novos triunfos da Ciência, da Tecnologia e do Poder. In: MAYOR. F; FORTI. A. Ciência \& Poder: Tradução de Roberto Leal Ferreira. - Campinas, SP: Papirus; Brasília: UNESCO, 1998.

FERREIRA, D. T. Temas socioambientais para o ensino de Ciências Naturais. 138 f. Dissertação (Mestrado). Programa de Pós-Graduação em Educação em Ciências e Matemáticas. Universidade Federal do Pará. Belém, 2011.

JAPIASSU, H. Ciências: questões impertinentes. Aparecida, SP: Idéias \& Letras, 2011.

JARA, C. J. A sustentabilidade do desenvolvimento local. Brasília: Instituto Interamericano de Cooperação para a Agricultura; Secretaria do Planejamento do Estado de Pernambuco, 1998.

KRASILCHIK, M. O professor e o currículo das ciências. São Paulo: EPU/EDUSP, 1987.

LIMA JÚNIOR, P. et al. Marx como referencial para análise de relações entre Ciência, Tecnologia e Sociedade. Ciência \& Educação, Bauru, v. 20, n. 1, p.175-194, 2014.

MARQUES, J. G. W. Pescando pescadores: ciência e etnociência em uma perspectiva ecológica. São Paulo: Núcleo de Apoio à Pesquisa sobre Populações Humanas e Áreas Úmidas Brasileiras (NUPAUB), USP, 2001.

MARTINS, V.S. Uma abordagem etnoecológica abrangente da pesca de polvos (octopus sp.) na comunidade de Coroa Vermelha (Santa Cruz Cabrália, Bahia). Dissertação (Mestrado). Programa de Pós-graduação em Sistemas Aquáticos Tropicais. Universidade Estadual de Santa Cruz. Ilhéus-BA, 2008.

MORAES, R. Mergulhos discursivos: análise textual qualitativa entendida como um processo integrado de aprender e inferir discursos. In: GALIAZZI, M. do C.; FREITAS, J. V. de (Org.). Metodologias emergentes de pesquisa em educação ambiental. 2a Ed. ljuí: Unijuí, p. 85-1 14, 2007.

MORAES, R.; GALIAZZI, M. do C. (2011). Análise textual discursiva. ljuí: UnijuÍ, $223 \mathrm{p}$.

MORIN, E. Ciência com consciência. Rio de Janeiro: Bertrand Brasil, 2005. 
NASCIMENTO, E. P. do. Trajetória da sustentabilidade: do ambiental ao social, do social ao econômico. Estudos Avançados, São Paulo, v. 26, n. 74, p. 51-64, 2012.

PINHEIRO, M. N. A. Educação crítico-reflexiva para um ensino médio científico-tecnológico: a contribuição do enfoque CTS para o ensinoaprendizagem do conhecimento matemático. 306 f. Tese (Doutorado). Programa de Pós-Graduação em Educação Cientifica e Tecnológica, Universidade Federal de Santa Catarina, Florianópolis, 2005.

RODRIGUES, A. L. F. O boto na verbalização de estudantes ribeirinhos: uma visão etnobiológica. Dissertação (Mestrado). Programa de PósGraduação em Teoria de Pesquisa do Comportamento. Universidade Federal do Pará, Belém-PA, 2008.

SANTOS, W. L. P. dos; SCHNETZLER, R. P. Educação em química: compromisso com a cidadania. ljuí: Ed. Unijuí, 2010.

SOUSA, E. M. et al. A importância das atividades lúdicas: uma proposta para o ensino de ciências. Congresso Norte Nordeste de Pesquisa e Inovação, Palmas-Tocantins, $2012 . \quad$ Disponível em: https://pdfs.semanticscholar.org/c67f/d6fa6e3a301 1096fael 623758ccc7 de0bda4.pdf . Acesso em: 13 set. 2014.

VASCONCELOS, E. R. de; FREITAS, N. M. S. O paradigma da sustentabilidade e a abordagem CTS: mediações para o ensino de ciências. Amazônia: Revista de Educação em Ciências e Matemáticas, Belém, v. 9, n.17, p. 89-108, 2012.

VAZ, C. R.; FAGUNDES, A. B; PINHEIRO, M. N. A. O surgimento da Ciência, Tecnologia e Sociedade (CTS) na educação: uma revisão. In: Simpósio Nacional de Ensino de Ciência e Tecnologia, 1, 2009. Disponível em: http://www.sinect.com.br/anais2009/artigos/1\%20CTS/CTS_Artigo8.pdf. Acesso em: 13 set. 2014.

VIEIRA, A.; REGINATO, M. J.; CHIEFFI, M. V. Os desafios do processo de elaboração das sequencias didáticas. Goiânia: Centro de Estudos e Pesquisas em Educação, Cultura e Ação Comunitária (CENPEC), 2009. (Currículo em Debate). 


\title{
RELAÇÃO ENTRE CIÊNCIA, TECNOLOGIA E SOCIEDADE: O QUE PENSAM OS ALUNOS DA LICENCIATURA INTEGRADA ${ }^{11,12}$
}

\author{
Lidiane Amaral Barbosa \\ Darlene Teixeira Ferreira \\ Nívia Magalhães da Silva Freitas \\ Josyane Barros Abreu \\ Elinete Oliveira Raposo \\ Nadia Magalhães da Silva Freitas
}

\section{INTRODUÇÃO}

Nas últimas décadas, o mundo passou por intensas transformações, produzidas pelo surgimento de novas tecnologias resultantes do intenso desenvolvimento científico. De acordo com Menon (1992), o avanço da ciência e da tecnologia deve ser considerado o empreendimento mais admirável da espécie humana. Podemos afirmar, no mesmo sentido, que o papel transformador do progresso científico tecnológico sobre a sociedade é considerado um dos aspectos mais marcantes das sociedades atuais (CACHAPUZ, 2011).

Essas transformações afetam todos os setores da sociedade e todas as áreas do conhecimento, pois é "[...]na tensão entre as possibilidades e os riscos criados pelo conhecimento das Ciências Naturais e sua tecnologia que vivemos no mundo contemporâneo" (DELIZOICOV, ANGOTTI, PERNAMBUCO, 2009, p. 127). Saber viver nessa tensão é fundamental nos dias de hoje. Portanto, a incorporação no processo educativo de discussões sobre a íntima relação que se estabeleceu nas últimas décadas entre Ciência, Tecnologia e Sociedade (CTS) é indispensável.

No ensino de Ciências, as discussões relacionadas à abordagem CTS passaram a ser incluídas a partir da década de 1980, com o intuito

\footnotetext{
${ }^{11}$ Licenciatura Integrada de Ciências, Matemática e Linguagens, do Instituto de Educação Matemática e Científica, da Universidade Federal do Pará.

${ }^{12}$ Publicado originalmente no Congreso Iberoamericano de Ciencia, Tecnología, Innovación y Educación, 2014, revisado e atualizado
} 
de enfatizar conteúdos socialmente relevantes e processos de discussão coletiva, de temas e problemas de significado e importância reais (BRASIL, 1998). Apesar do reconhecimento das possibilidades pedagógicas, pautadas nessa abordagem, é válido ressaltar que essas discussões só serão introduzidas nas salas de aulas se os professores reconhecerem que vivemos em uma sociedade permeada pela ciência e pela tecnologia e, portanto, a abordagem CTS é importante para a formação de cidadãos cônscios e capazes de tomar decisões fundamentadas (SANTOS, 2003).

Para isso, é fundamental que, ao longo da sua formação, o professor tenha acesso a essas discussões, de modo que possa adquirir condições para introduzir questões relacionadas a CTS em sua sala de aula. Assim, buscando conhecer como essas questões são apresentadas em cursos de formação de professores, realizamos esta pesquisa com os seguintes objetivos: (a) destacar a importância do enfoque CTS nos cursos de formação de professores, em especial professores que irão ensinar ciências; (b) investigar a compreensão dos estudantes de um curso de licenciatura sobre a abordagem CTS e (c) verificar se os alunos reconhecem a importância da abordagem CTS no/para o ensino de Ciências.

Este texto está organizado em quatro seções, além desta introdução. Na seção intitulada "CTS e formação de professores", intencionamos apresentar como o enfoque CTS tem sido introduzido na formação de professores. Na seção "Aspectos metodológicos", apresentamos as nossas escolhas metodológicas, enfatizando o tipo de abordagem de pesquisa, descrição de como foi realizada a pesquisa de campo, o instrumento de coleta de dados e a forma como os dados foram analisados. Na seção "O que pensam os alunos sobre a relação entre ciência, tecnologia e sociedade", apresentamos as categorias organizadas a partir da leitura e da análise dos dados constituídos, discutindo-as a partir do referencial teórico pertinente; e, por fim, as "Considerações Finais". 


\section{CTS E FORMAÇÃO DE PROFESSORES}

Não há dúvidas sobre o poder transformador do conhecimento, pois, hoje, mais do que em qualquer outra época, possuímos a consciência de que a ciência é uma prática social relevante e necessária para resolução de muitos problemas da humanidade, e é considerada a forma mais eficiente de gerar conhecimentos significativos no contexto das sociedades contemporâneas (VALE, 2009). Segundo Santos (2011), o conhecimento científico e tecnológico marca, de forma significativa, as sociedades dos países ditos desenvolvidos; aliás, esse desenvolvimento esteve e está estreitamente associado ao modo como foram valorizando e usando a ciência e a tecnologia.

As marcas deixadas pela Ciência e pela Tecnologia na sociedade precisam ser analisadas e avaliadas, pois, como destaca Bazzo (2010), as avaliações da ciência e da tecnologia e de suas repercussões na sociedade precisam seguramente tomar rumos mais claros e intensos nas atividades de todas as escolas. O fato é que precisamos retirar a Ciência e a Tecnologia de seus pedestais inabaláveis da investigação desinteressada da verdade e dos resultados generosos para o progresso humano.

Para tanto, necessitamos de um ensino mais crítico, mais político e que resulte na formação de cidadãos. Para Chassot (2003, p. 109), "[...] um ensino mais político não se anuncia, se faz. Ele ocorre quando mostramos a serviço de quem está a ciência que nós ensinamos". Fazer esse ensino, pressupõe conhecimento das questões emergentes na atual sociedade, daí a necessidade de formar professores capazes de despertar para a cidadania. Nesse sentido, a educação é substancialmente importante para discutir as implicações CTS num processo de contribuição para formar cidadãos críticos, capazes de compreender e intervir no mundo, de modo a contribuir para a melhoria da qualidade de vida. 
Para Freire (1987), educação se relaciona com conhecimento crítico da realidade. Nesse sentido, é de extrema importância problematizar as questões CTS na formação de professores, em especial de professores que irão ensinar ciências, com a intenção de despertar uma consciência crítica diante dos inúmeros avanços tecnológicos que nos trazem muito conforto, mas que também produzem diversos malefícios. A educação apresenta, muitas vezes, a necessidade de romper com o paradigma vigente de um currículo tradicional, para mostrar aos alunos a importância de se refletir sobre as vantagens e as desvantagens da Ciência e Tecnologia na sociedade.

Chassot (2003) enfatiza que não devemos apresentar para nossos alunos a imagem de uma ciência neutra, centrada numa verdade objetiva e de construção progressiva, pois na ciência não existe uma verdade imutável, mas sim algumas verdades que são transitórias e que, inclusive, de tempos em tempos se transformam. Não podemos ver a ciência somente como uma fada benfazeja capaz de realizar maravilhas (mudanças tecnológicas) sem nenhum prejuízo à sociedade.

No entanto, o currículo, em especial o currículo da disciplina Ciências, não possibilita uma visão ampla da realidade sobre a relação CTS, pois o conteúdo é apresentado de forma mecanicista, resultado de um currículo cartesiano e positivista. Ao se elaborar um currículo transversal, possibilita-se formar um caráter analítico-reflexivo, que conduza os alunos a uma sensível mudança de pensamento. O desafio dos cientistas e intelectuais, de acordo com Behrens (2005), é como instigar professores a adotarem uma prática pedagógica que supere a fragmentação e a reprodução do conhecimento.

É válido destacar que não devemos encarar apenas como responsabilidade do ensino de Ciências a abordagem de temas que discutam as relações CTS em sala de aula. As questões relacionadas à CTS envolvem diferentes domínios, a saber: social, econômico, político, cultural, ambiental, entre outros, daí a necessidade de realizar 
abordagens que sejam interdisciplinares. Nesse sentido, Santos (2011) ressalta que o ensino das Ciências, para todos os níveis de escolaridade, deve preocupar-se com outras dimensões do saber, para além dos conteúdos disciplinares específicos. Para tal, é necessário conhecer os contextos nos quais os problemas ocorrem, as variáveis implicadas e os valores que subjazem à procura de soluções.

Compreender as relações CTS é também compreender o meio em que se vive e tomar para si a responsabilidade de atuar de forma plausível num mundo globalizado e em constante modificação tecnológica; é, ainda, compreender que a Ciência representa uma eterna busca (CHASSOT, 2003). No entanto, é necessário reconhecer, também, que apesar de um grande avanço científico tecnológico, a Ciência não consegue responder a todas as necessidades sociais da humanidade. Em muitos casos, torna-se frágil e impotente diante da ausência de soluções para os inúmeros problemas que afligem a sociedade.

Em relação às limitações da Ciência, Chassot (2003) afirma que elas são cada vez mais evidenciadas ao se verificar o quanto a Ciência não resolve os mais angustiantes problemas da humanidade, como a fome; ao contrário, cria novas fontes de problemas, como o desemprego, originado de inovações tecnológicas. Fato destacado por Martins e Paixão (2011), quando afirmam que no mundo o número de pessoas subnutridas continua a ser muito alto e que, apesar dos acordos e compromissos assinados em frequentes encontros internacionais, o progresso tem sido praticamente imperceptível. Enquanto para 0 mundo ocidental a fome já há muito não se constitui um problema ou realidade, para grande parte da população da Ásia ou da África Central e oriental, a realidade é a fome permanente.

Logo, temos que considerar, conforme Bazzo (2010), que a utilização dos avanços tecnológicos em relação à sociedade é colocada em discussão, sempre na busca de respostas a esta intricada relação, que ainda deixa de fora de seus benefícios grande parte da Sumário $\triangle$ 
população. Decerto, a educação é um dos caminhos para discutirmos tais questões, pois, como destaca Santos (2011), se a educação é um dos indicadores de desenvolvimento econômico e das condições de saúde, é por meio dela que as mudanças na sociedade são possíveis.

\section{ASPECTOS METODOLÓGICOS}

Para a realização desta pesquisa, optamos pelo paradigma qualitativo. A abordagem qualitativa, segundo Minayo (2016), permite a compreensão da realidade e possibilita o aprofundamento no mundo dos significados, sem a preocupação de quantificar sujeitos e opiniões. Para a referida autora, é o tipo de enquadramento mais apropriado quando se pretende trabalhar com o universo de significados, de aspirações, das crenças e valores.

A pesquisa qualitativa pode também ser entendida, segundo Richardson et al. (2009), como uma tentativa de compreender de maneira mais detalhada os significados e as situações apresentadas pelos entrevistados. Godoy (2005) ressalta, ainda, que esse tipo de pesquisa possui lugar de destaque dentre as várias possibilidades de estudos dos fenômenos que envolvem as complexas relações sociais estabelecidas em diversas ambiências.

Realizamos pesquisa bibliográfica e pesquisa de campo. A pesquisa bibliográfica, segundo Pádua (2012, p. 55), é fundamentada "[...] nos conhecimentos de biblioteconomia, documentação e bibliografia; sua finalidade é colocar o pesquisador em contato com o que já se produziu e registrou a respeito do seu tema de pesquisa". Já a pesquisa de campo "[...] visa reunir e organizar um conjunto comprobatório de informações" (CHIZZOTTI, 2010, p. 103).

A pesquisa de campo foi realizada durante o desenvolvimento do tema "Relações entre Ciência, Sociedade e Cidadania" (a proposta curricular do Curso em que a pesquisa ocorreu está organizada por eixos temáticos, temas e assuntos, numa perspectiva interdisciplinar), do 
Curso de Licenciatura Integrada em Ciências, Matemática e Linguagens, da Universidade Federal do Pará. Para o desenvolvimento do tema, foi planejada uma situação de estudo denominada "A abordagem temática com enfoque CTS: usos e abusos da energia nuclear".

A situação de estudo foi organizada em sete episódios. Para este texto, trazemos a análise dos dados levantados a partir da aplicação de um questionário, precisamente de duas questões, a saber: (1) necessidade de uma formação científica em um mundo marcado pela presença da Ciência e da Tecnologia e (2) Importância do enfoque CTS para educação, notadamente para o ensino de Ciências. Participaram desse episódio 28 Alunos.

A seleção dos alunos ocorreu por meio de amostragem não probabilista intencional. De acordo com Marconi e Lakatos (2011), nesse tipo de amostragem não há aplicação de fórmulas estatísticas para cálculo. As amostras não probabilistas intencionais, ainda segundo Marconi e Lakatos (2011, p. 38), são utilizadas quando "[...] o pesquisador está interessado na opinião de determinados elementos da população, mas não representativos dela". As respostas obtidas por meio dos questionários foram analisadas e organizadas em categorias. Para análise das respostas, utilizamos os princípios da análise de conteúdo, proposta por Bardin (2011).

\section{- que pensam os alunos sobre a relaçÃo entre ciênCIA, TECNOLOGIA E SOCIEDADE}

Celulares, internet, computadores... a vida hoje é permeada pela tecnologia. Poucos setores de nossa vida não são afetados pela ciência e tecnologia. Nesse cenário, é impensável uma formação que não possibilite ao cidadão contato com discussões concernentes à relação entre a ciência e a tecnologia e as implicações desta relação. São 
essas discussões que possibilitam a formação de cidadãos críticos e capazes de tomar decisões fundamentas.

As respostas às questões foram organizadas em duas categorias, a saber: (1) Formação científica: uma necessidade e (2) CTS no ensino de Ciências. Na categoria "Formação científica: uma necessidade", identificamos três subcategorias, a saber: (1) desenvolver a capacidade crítica; (2) tomada de decisão e (3) não compreendem a necessidade da formação científica. Na categoria "CTS no ensino de Ciências", observamos a emergência de questões relacionadas à (1) aproximação do conhecimento científico; (2) relação de dependência e (3) formação para cidadania. Por sua vez, os sujeitos da pesquisa (alunos) foram identificados pela palavra Aluno, seguida de número.

\section{Formação científica: uma necessidade}

Desenvolver a capacidade crítica

O cidadão se depara cada vez mais com temas controversos produzidos pela interação da ciência e da tecnologia, como por exemplo, os alimentos transgênicos. Diante de temas como esse, os cidadãos devem saber refletir de forma crítica sobre os aspectos implicados, ou seja, da produção e do consumo desses alimentos. Para tanto, é fundamental que o indivíduo desenvolva sua capacidade crítica.

Esse desenvolvimento é possível, de acordo com Gil-Pérez e Vilches (2011), por meio da educação científica, considerada, hoje, pelos especialistas, uma exigência urgente, uma vez que representa um fator essencial para o desenvolvimento das pessoas e dos povos. $O$ enfoque CTS, na opinião dos alunos, contribui, de forma significativa, para o desenvolvimento dessa capacidade, como podemos atestar nas seguintes falas: 
Aluno 10: a formação de um olhar crítico e saber lidar com as questões que envolvem CTS de forma sabia, responsável e consciente;

Aluno 11: formar alunos críticos, para que não pensem que tudo que leem ou veem, ou o que o professor ensina é verdade.

Tomada de decisão

De posse de conhecimentos e da possibilidade de realizar reflexões críticas sobre a forma de se relacionar com o mundo, o cidadão pode tomar decisões fundamentadas. Não basta decidir sobre consumir ou não consumir os produtos oriundos da tecnologia la exemplo dos transgênicos), é necessário saber construir argumentos para defender seu posicionamento. Nesse sentido, o enfoque CTS pode atender as demandas atuais da educação científica para que ela esteja comprometida com a formação para cidadania e para a constituição de uma sociedade justa e igualitária (SANTOS, 2011). Vejamos o que expressam os alunos:

Aluno 3: o aluno pode debater e argumentar a respeito de um determinado assunto;

Aluno 21: que ele (o aluno) possa estar preparado para entender e argumentar sobre os acontecimentos científicos e tecnológicos.

Podemos depreender, então, que a tomada de decisão também ganhou espaço nas falas dos alunos.

\section{Não compreendem a necessidade da formação científica}

Para Chassot (2003), a Ciência é uma linguagem. Sendo assim, ser alfabetizado cientificamente é saber ler a linguagem em que está escrita a natureza; portanto, é um analfabeto científico aquele que não é capaz de realizar uma leitura do universo. Assim, entender a Ciência, de acordo com Chassot (2003), nos facilita no controle e na previsão das transformações que ocorrem na natureza, nos fornecendo 
condições de fazer com que essas transformações sejam propostas, para que conduzam a uma melhor qualidade de vida.

No entanto, apesar de vivermos em um mundo repleto de produtos da ciência e da tecnologia, ainda há estudantes que não conseguem ou possuem dificuldade de compreender a necessidade de uma formação científica. Dos 28 alunos participantes desta pesquisa, 12 deixaram a questão relacionada à necessidade de formação científica em branco.

\section{CTS no ensino de Ciências}

Aproximação do conhecimento científico

Os conteúdos de ciências, durante muito tempo, foram apresentados como sendo um conhecimento isolado, alheio à realidade dos alunos. Ultimamente, no entanto, de acordo com Lima e Grillo (2008), estão sendo revistos projetos educativos nas áreas de ciências que primam pela seleção de conteúdos escolares com o objetivo de transmitir informações, nomenclatura e definições e pelas descrições de fenômenos naturais a serem memorizados.

Temos que elaborar propostas para o ensino de Ciências que possuam o compromisso de gerar conhecimentos que permitam ao estudante utilizá-los a seu favor, qualificando os alunos para o exercício de seus direitos e suas responsabilidades. Nesse sentido, o enfoque CTS se coaduna com essa proposta, pois possui relação direta com o dia a dia dos estudantes, fato reconhecido pelos participantes da pesquisa, como destaca o aluno:

Aluno 21: CTS pode utilizar questões do dia a dia, do meio ambiente ensinando para os alunos na prática.

De fato, aprendemos em múltiplas situações do cotidiano, em múltiplos lugares, de modo que torna possível apreender, criticamente, os conteúdos socioculturais que nos constituem. 
Relação de dependência

Os alunos apresentaram uma visão de dependência entre a Ciência e a Tecnologia, o que pode ser reflexo da visão do modelo linear de desenvolvimento: quanto mais ciência, mais tecnologia; mais riqueza é igual mais bem estar social. Modelo que, por muito tempo, foi aceito pela sociedade; no entanto, Bazzo (2010) ressalta que o desenvolvimento tecnológico não é um processo linear de melhorias, e, sim, um processo multidirecional.

Formação para cidadania

Pensar em trabalhar com o enfoque CTS é pensar em adotar abordagens de ensino que favoreçam a autonomia dos estudantes, responsabilizando-os pelo seu próprio aprendizado; além de favorecer a construção de visão crítica, reflexiva, necessária à tomada de decisão, que está fundamentada em argumentos de natureza técnica, científica, social, ética, entre outras, relevantes ao processo educativo. Discussões sobre questões relacionadas à CTS pressupõem uma formação ambiental, por meio da formação inicial de professores.

Os participantes da pesquisa reconhecem que o enfoque CTS contribui para a formação para a cidadania, como podemos atestar nas seguintes falas:

Aluno 12: O ensino CTS nas escolas é de fundamental importância para a formação de um aluno questionador e reflexivo;

Aluno 27: CTS veio propor um ensino diferenciado, no qual os alunos são estimulados a pesquisar e refletir sobre o seu papel na sociedade.

Nesse contexto, acreditamos que uma abordagem temática interdisciplinar é fundamental para contribuirmos com a formação do pensamento crítico (FAZENDA, 2008). 


\section{CONSIDERAÇÕES FINAIS}

Em um mundo cada vez mais marcado pela presença da Ciência e da Tecnologia, é impossível pensar em uma formação para cidadania que não problematize as relações CTS. Atualmente, todos os aspectos da nossa vida são influenciados pela tecnologia, resultado do avanço na produção dos conhecimentos científicos: nossa comunicação, nossa saúde, nossa cultura, nossos transportes, nossa economia, tudo passou a ser fortemente influenciado pela tecnologia.

Surge, assim, a necessidade de ser alfabetizado cientificamente, não só para realizar a leitura dos fenômenos naturais, mas também para saber como agir no dia a dia. A alfabetização científica pode ocorrer em vários espaços, pois não é privilégio apenas da escola divulgar esses conhecimentos, haja vista que podem ser construídos a partir de múltiplas relações de interação em diferentes ambientes. No entanto, no ambiente escolar, notadamente nas aulas de Ciências, essas discussões podem estar presentes mediante adoção do enfoque CTS.

Ressaltamos que, para esse tipo de abordagem chegue às salas de aula, os professores devem estar preparados para introduzirem questões que rompam com conteúdos apenas disciplinares. Daí a necessidade de apresentar estratégias que envolvam questões CTS durante a formação dos professores, que pode ser a inicial ou a continuada. O importante é que o professor tenha acesso à fundamentação teoria e às práticas de CTS, para que possam, de posse desses conhecimentos, adotá-los em suas aulas.

Observamos manifestações que destacaram que a abordagem CTS: (a) aproxima os alunos dos conteúdos, pois apresenta relação com o seu cotidiano; (b) amplia a percepção de determinados temas; (c) faz o aluno perceber o duplo caráter da ciência e da tecnologia; (d) contribui para a formação de cidadãos; (e) torna o aluno mais crítico; e (f) rompe com o modelo tradicional de ensino. Desse modo, foi possível 
observar que os alunos perceberam a importância do enfoque CTS para educação científica.

\section{REFERÊNCIAS}

AIKENHEAD. (1994). What is STS science teaching? In: SOLOMON, J., AIKENHEAD, G. STS education: international perspectives on reform. New York: Teachers College Press, p.47-59.

BARDIN, Laurence. (2011). Análise de conteúdo. São Paulo: Edições 70.

BAZZO, W. A. Ciência Tecnologia e Sociedade: e o contexto da educação tecnológica. 3 ed. Ed. UFSC, 2010.

BEHRENS, M. A. O paradigma emergente e a prática pedagógica. Petrópolis, RJ: Vozes, 2005.

CACHAPUZ, A. F. Tecnociência, poder e democracia. In: SANTOS, W. L. P. dos; AULER, D. (Org.). CTS e Educação Científica: desafios, tendências e resultados de pesquisas. Brasília: Editora Universidade de Brasília, 2011. p. 49-72.

CHASSOT, A. Alfabetização científica: questões e desafios para a educação. 3 Ed. ljuí: Ed. Unijuí, 2003.

FARIAS, F. Saga da Amazônia. In: Cd Cantorias 1 - Eleoma, Geraldo Azevedo, VitaL Farias e Xangai. Salvador: Kuarup, 1984.

FREIRE, P. Pedagogia da esperança: um reencontro com a Pedagogia do Oprimido. Rio de Janeiro: Paz e Terra, 1992.

FAZENDA, I. O Que é interdisciplinaridade? São Paulo: Cortez, 2008.

GIL-PEREZ, D.; VILCHES, A. Importância da educação científica na sociedade actual. In: CACHAPUZ, A. A necessária renovação do ensino das ciências. São Paulo: Cortez, 2005.

GODOY, A. S. Pesquisa qualitativa: tipos fundamentais. Revista de Administração de Empresas, São Paulo, v. 35, n. 3, p. 20-29, 2005. 
LÓPEZ, J. L. L., CEREZO, J. A. L. Educación CTS en acción: enseñanza secundaria y universidad. In: GARCÍA, M. I. G., CEREZO, J. A. L., LÓPEZ, J. L. L. Ciencia, tecnología y sociedad: una introducción al estudio social de la ciencia y la tecnología. Madrid: Editorial Tecnos S. A., 1996.

MINAYO, M. C. de. O desafio da pesquisa social. In: MINAYO, M. C. de S. (Org.); DELANDES, S. F.; GTOMES, R. Pesquisa social: teoria, método e criatividade. Petrópolis-RJ: Vozes, 2016. p. 9-28. (Série Manuais Acadêmicos).

PRAIA, J; CACHAPUZ, A. F. Ciência-Tecnologia-Sociedade: um compromisso ético. Revista Iberoamericana de Ciência, Tecnología y Sociedade, Madrid, v. 2, n. 6, p.173-194, 2005.

RAMSEY, J. The science education reform movement: implications for social responsibility. Science Education, USA, v. 77, n. 2, p. 235-258, 1993.

RICHARDSON, R. J. et al. Pesquisa social: métodos e técnicas. 3. ed. rev. ampl. São Paulo: Atlas, 2009.

RUBBA, P. A. Integration STS into school science and teacher education: beyond awareness. Theory into Practice, USA, v. 30, n. 4, p. 303-315, 1991.

SANTOS, W. L. P.; AULER, D. (Org). CTS e educação científica: desafios, tendências e resultados de pesquisas. Brasília: Editora Universidade de Brasília, 2011.

SANTOS, W. L. P. dos; SCHNETZLER, Roseli Pacheco. Educação em química: compromisso com a cidadania. 3. ed. ljuí: Ed. Unijuí 2003.

SOLOMON, J. Science technology and society courses: tools for thinking about social issues. International Journal of Science Education, USA, v. 10, n. 4, p 379-387, 1988.

SOLOMON, J. Teaching science, technology and society. Buckingham: Open University Press, 1993.

THIER, H. D. Societal issues and concerns a new emphasis for science education. Science Education, USA, v. 69, n. 2, p.155-162, 1985. 

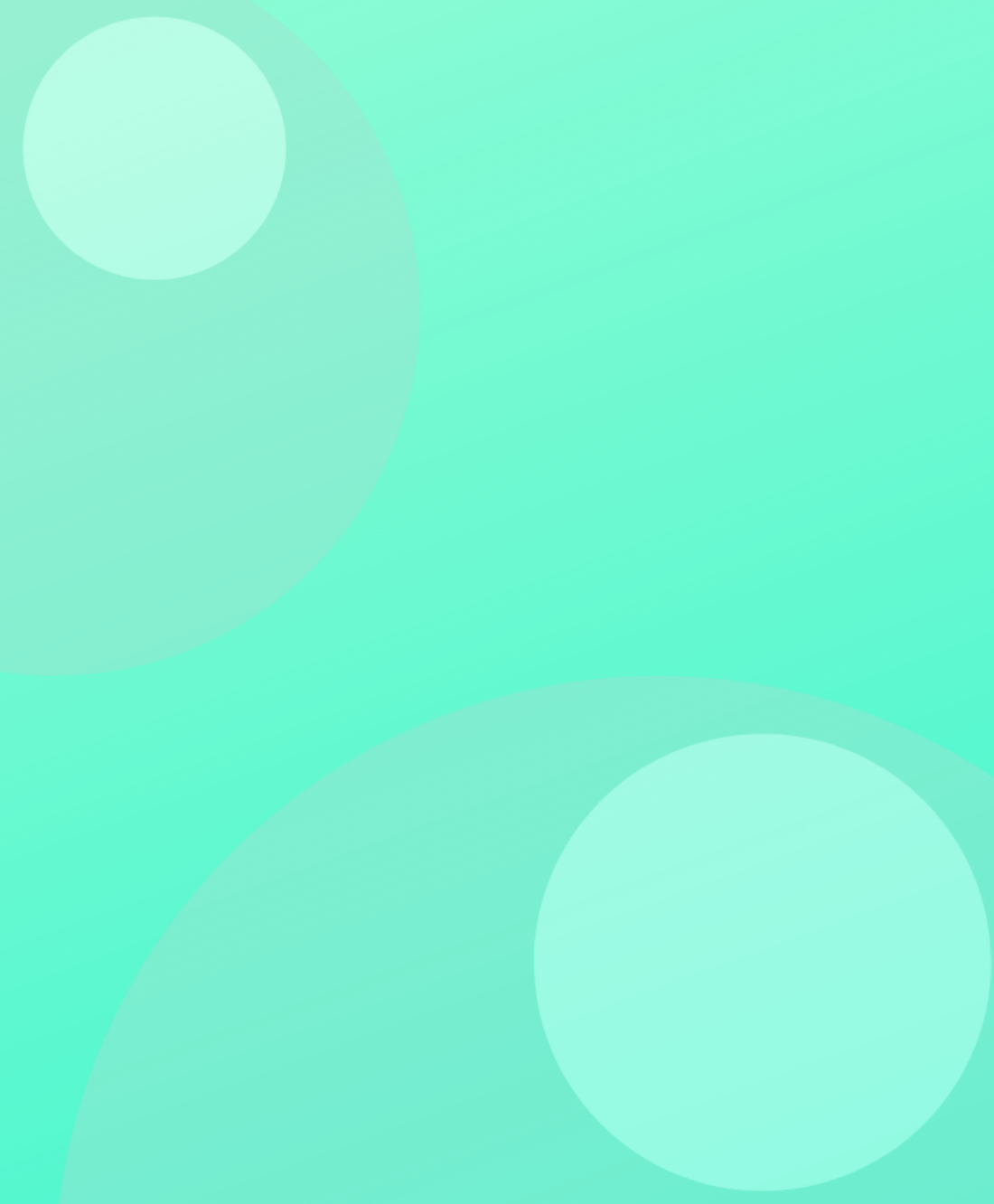